András Tilcsik | University of Toronto

\title{
Statistical Discrimination and the Rationalization of Stereotypes
}

\author{
Forthcoming: American Sociological Review \\ https://doi.org/10.1177/0003122420969399
}

\begin{abstract}
The theory of statistical discrimination is a dominant social scientific framework for understanding discrimination in labor markets. To date, the literature has treated this theory as a model that merely explains employer behavior. This article contends that the idea of statistical discrimination, rather than simply providing an explanation, can lead people to view social stereotyping as useful and acceptable and thus help rationalize and justify discriminatory decisions. A preregistered survey experiment with more than 2,000 participants who had managerial experience shows that exposure to statistical discrimination theory strengthened people's belief in the accuracy of stereotypes, their acceptance of stereotyping, and the extent to which they engaged in gender discrimination in a hiring simulation. Reading a critical commentary on the theory mitigated these effects. These findings imply that theories of discrimination, and the language associated with them, can rationalize — or challenge the rationality ofstereotypes and discrimination and, as a result, shape the attitudes and actions of decision-makers in labor markets.
\end{abstract}

\section{Keywords}

discrimination, stereotypes, labor markets, gender, race, social theories, economics

The question of why racial and gender discrimination persist in contemporary labor markets has led to widespread scholarly debate across the social sciences (Bohnet 2016; Castilla 2008; Charles and Guryan 2011; Pager and Shepherd 2008; Quillian et al. 2017; Ridgeway 2011). One important contribution of sociology to this conversation has been to illuminate the changing nature of prejudice and discrimination in recent decades. Sociologists have documented how blatant prejudice has given way to more subtle and covert forms of bias in the post-Civil Rights era (e.g., Bonilla-Silva and Dietrich 2011; Quillian 2006; Ridgeway 2011); shed light on the status beliefs and stereotypes that shape employer decisions in modern labor markets (e.g., Ridgeway 1997; Rivera 2020); and identified various structural mechanisms that underlie contemporary forms of discrimination (e.g., Baron and Bielby 1980; Bonilla-Silva 1997; Ray 2019; Reskin 2012; Ridgeway and Correll 2004; Small and Pager 2020).

Economists, for their part, have theorized labor market discrimination from a different angle, building mathematically sophisticated models that attribute discrimination to the deliberate actions of profit-maximizing firms or utility-maximizing individuals (Charles and Guryan 2011; Small and Pager 2020). Although the fundamental assumptions behind these models have changed relatively little in the past four decades (Guryan and Charles 2013), the economic view on discrimination has had significant influence on social scientific debates, legal decisions, corporate practices, and public policy discussions (Ashenfelter and Oaxaca 1987; ChassonneryZaïgouche 2020; Dobbin 2001; Rivera 2020). 
Perhaps the most influential economic model of discrimination is the theory of statistical discrimination (Aigner and Cain 1977; Arrow 1973; Phelps 1972; see National Research Council 2004). When applied to labor markets, this theory posits that employers have imperfect information about the future productivity of job candidates, which gives them an incentive to use easily observable ascriptive characteristics, such as race or gender, to infer the expected productivity of applicants (Correll and Benard 2006; England 1994). Statistically discriminating employers rely on their beliefs about group statistics to evaluate individuals. In this model, discrimination does not arise from animus or antipathy toward members of a group; rather, it is portrayed as a rational solution to an information problem. Profit-maximizing employers use all the information available to them, and when individual-specific information is limited, they use group membership as a proxy (Bertrand and Duflo 2016).

Statistical discrimination theory has been a workhorse of economic analyses of labor market inequality since the 1970s and has become one of the dominant social scientific frameworks for understanding discrimination (Guryan and Charles 2013; National Research Council 2004). The theory is frequently featured in popular media, the business press, and policy papers. It is also a staple in textbooks used in introductory economics courses, which - taken by more than one million students in North America each year - serve "as an important conduit for the transmission of economic theory and values to the population at large" (Green 2012:190). Explanations akin to statistical discrimination also emerge frequently when employers attempt to account for their own discriminatory decisions (Bracic 2018; Pager and Karafin 2009; Pedulla 2020). ${ }^{1}$

In the social scientific literature on discrimination, considerable debate has focused on the accuracy and explanatory power of statistical discrimination theory and, more broadly, on the rationality of employers' discriminatory decisions. Much of the literature on racial discrimination, for example, "attempts to discern whether discrimination stems primarily from racial animus or from ... more instrumental adaptations to information shortages," such as statistical discrimination (Pager and Shepherd 2008:193). Traditionally, these debates treat statistical discrimination as a model that merely explains employer behavior. In contrast, this article contends that statistical discrimination theory is a powerful frame that shapes the extent to which decision-makers view stereotyping and discrimination as rational and acceptable. Building on economic sociology, social psychology, and the sociology of knowledge, I argue that - rather than merely explaining discrimination — statistical discrimination theory helps rationalize and justify discriminatory decisions. I predict that exposure to the theory will strengthen people's belief in the accuracy of stereotypes, their acceptance of stereotyping, and their propensity to engage in discrimination based on ascriptive group membership.

Social scientists have long recognized that social theories can influence reality rather than merely describe it (Hollis 1987; Merton 1948; Sztompka 1991), and the insight that ideas shape economic behavior is central to economic sociology (Dobbin 1994b; Fligstein 1993; Guillén 1994; Weber 1905; Zelizer 1979). Building on these foundations, I argue that the theory of statistical discrimination and the associated rhetoric of economic rationality can influence behavior by providing moral authorization to rely on social stereotypes and engage in discrimination. Unlike most other accounts of discrimination, statistical discrimination theory explicitly portrays discriminatory decisions as rational and emphasizes the cognitive and economic utility of relying on group estimates (Pager and Karafin 2009). Economists tend to frame statistical discrimination as "the optimal solution to an information extraction problem" (Autor 2003:11) and sometimes describe it as "efficient" and even "fair" (e.g., Autor 2003; Bertrand and Duflo 2016; Norman 2003).

To be sure, many social science theories do not shape the aspects of reality they attempt to explain, and even widely accepted theories do not necessarily have a substantial influence. To 
shed some light on the conditions under which theories of discrimination are more or less likely to affect behavior, I contrast statistical discrimination theory with the other dominant economic perspective on discrimination, Becker's (1957) taste-based model, which focuses on discrimination that stems from animus toward another group. Unlike statistical discrimination theory, which taps into the culturally valued discourse of instrumental rationality and frames discrimination as a logical solution to an information problem, the taste-based model is about negative attitudes, such as overt racial prejudice and sexism, that tend to be publicly disavowed and are often perceived as socially unacceptable (Pager and Quillian 2005). Thus, in cultural contexts where blatant racist and sexist preferences tend to be deemed offensive, the taste-based model is less likely to provide an acceptable justification for discrimination. But how the theory of statistical discrimination itself is framed likely matters, too. When it is presented in a critical light — with a discussion of its problematic aspects highlighted in the economics literature - it is less likely to provide compelling moral authorization for discrimination. Thus, the presence of a critical commentary will likely mitigate the effects of statistical discrimination theory.

To test these predictions, I conducted a vignette experiment using a sample of individuals with managerial experience. Participants were exposed to (1) the idea of statistical discrimination, (2) a set of neutral, unrelated materials, (3) the taste-based model, or (4) statistical discrimination theory alongside a critical commentary. Exposure to statistical discrimination theory increased participants' belief in the accuracy of stereotypes, their acceptance of stereotyping, and the extent of gender discrimination in a hiring simulation. Adding a critical commentary to the standard description of the theory alleviated these effects. Together, these findings point to a single conclusion: how we theorize and talk about discrimination matters. Our theories can rationalize - or question the rationality of - stereotypes and discrimination and thus shape the attitudes and actions of decision-makers in labor markets.

\section{ECONOMIC THEORIES AND BEHAVIOR}

Sociologists have long emphasized the importance of ideas and beliefs in shaping social and economic behavior. This was the central theme of Weber's The Protestant Ethic and the Spirit of Capitalism (1905) and Merton's (1948) influential essay on the self-fulfilling prophecy, which built on and popularized the Thomas theorem: "If men define situations as real, they are real in their consequences." Building on these insights, economic sociologists have built a vibrant research program documenting how ideas about what is rational and legitimate influence economic institutions and behaviors (e.g., Dobbin 1994b; Fligstein 1993; Guillén 1994; Meyer and Rowan 1977; Scott 2013; Zelizer 1979).

The social sciences are an important source of ideas about what constitutes rational and legitimate behavior. Indeed, numerous scholars have emphasized the potential of social theories to shape reality, rather than merely describing it. As Sztompka (1991:84) noted, "a theory of human action, social order or social development may directly influence the human beings who are at once its ultimate referents and its ultimate addresses, and in effect transform the very processes about which it makes its assertions." Or, as Hollis (1987:4) quipped, "Social theory, being itself in circulation among its subjects, is tied to its own tail."

Not every social theory comes to influence its subjects, but some theories do have the potential to shape institutional designs, organizational arrangements, or individual attitudes (Dobbin 2009; Fourcade, Ollion, and Algan 2015; Frank, Gilovich, and Regan 1993). Social scientific ideas can affect people's mental models of the world, shape norms, and offer terms and metaphors for interpreting ambiguous situations (Ferraro, Pfeffer, and Sutton 2005).

Social psychologists have demonstrated the causal effect of ideas by randomly assigning experimental participants to be exposed to different theories of human behavior and then 
examining the resulting changes in people's views. For example, exposure to biological (rather than sociocultural) explanations for gender differences caused people to view human attributes as less mutable and led to greater endorsement of gender stereotypes (Brescoll and LaFrance 2004). At a more macro level, sociologists have explored how social scientific ideas may influence institutions and organizations (e.g., Fourcade 2009; Hirschman and Berman 2014; Kalev, Dobbin, and Kelly 2006) and have documented, for example, how corporate equal opportunity experts align diversity programs with ideas from the social sciences, such as the concept of institutional discrimination or the idea of cognitive bias (Dobbin 2009).

\section{The Influence of Economic Ideas}

Given the dominant position of economics in Western societies, economic theories have great potential to influence the world beyond academia (Blyth 2002; Ferraro et al. 2005; Fourcade 2009; Marglin 2008). As Fourcade and colleagues (2015:109) note, "Economic reasoning, expertise, and technologies permeate capitalist activities, culture (including the media and bestseller lists), and institutions." The influence of economics is well-documented in higher education, business, government, and the press (Babb 2004; Berman 2017; Ferraro et al. 2005; Fourcade 2009; Jung and Shin 2019). Economic sociologists, for example, have highlighted the pervasive influence of agency theory in transforming corporate behaviors and structures over the past four decades (Dobbin and Jung 2010) and suggested that some economic theories come to function as behavioral prescriptions and scripts rather than as mere descriptions of how economic agents behave (Jung and Dobbin 2016).

Some of this influence is direct. Economists in government or corporate positions dispense advice and help design policies (e.g., Babb 2004; Berman 2017; Fourcade 2009), and, as performativity theorists suggest, some economic models provide concrete tools that shape the construction of markets (e.g., Mackenzie 2008). In other cases, the influence of economics is less direct. A crucial source of indirect influence is that economics provides a "cognitive infrastructure" (Hirschman and Berman 2014:779) for understanding the world and fosters an economic style of reasoning among decision-makers (Berman forthcoming). Consistent with this view, researchers have found that exposure to mainstream economics tends to encourage self-interested behavior and inhibit cooperation. In one study, students in an introductory microeconomics course came to view purely self-interested actions as more appropriate than they did before enrolling in the course, and they showed greater change in this direction than did students in the control condition, an introductory astronomy course (Frank et al. 1993).

This line of research on the influence of economic ideas might call to mind Keynes's famous (if exaggerated) assertion that "practical men, who believe themselves to be quite exempt from any intellectual influence, are usually the slave of some defunct economist." Of course, not all economic ideas have the potential to influence behaviors (Felin and Foss 2009; Schudson 1989). Many theories are simply too abstract to have any clear behavioral or policy implications (Mirowski and Nik-Khah 2007; Zuckerman 2010). In other cases, the content or language of an economic theory might be at odds with broader cultural norms and assumptions, which would limit the theory's acceptance, diffusion, and influence (Brisset 2016; Ferraro et al. 2005).

These perspectives suggest economic agents are neither blindly obedient to the dictates of economic theories nor completely immune to their influence. Economic ideas are heterogeneous in their potential for influencing behavior. A theory that fits with broader cultural frames is more likely to resonate with audiences and ultimately be viewed as acceptable, valid, and useful than one that is inconsistent with existing social norms and assumptions (Brisset 2016; Ferraro et al. 2005; Schudson 1989). And, conditional on having achieved some level of diffusion and acceptance, a theory that offers relatively clear behavioral prescriptions is more likely to have substantive influence than one that provides ambiguous practical implications (see Mirowski 
and Nik-Khah 2007; Schudson 1989). In what follows, I review the theory of statistical discrimination and argue that it meets these necessary conditions-cultural resonance and prescriptive specificity - for influencing, rather than merely explaining, economic behavior. To highlight the distinctive aspects of statistical discrimination theory and situate it in a broader social scientific context, I begin by briefly summarizing some of the most important sociological ideas relevant to discrimination. I then turn to the economic literature on the topic.

\section{Sociological Perspectives}

A vast social scientific literature on labor market discrimination has developed over the past six decades. One important contribution of sociology to this literature has been an elaboration of how the nature of discrimination and other inequality-generating processes have changed since the Civil Rights era. Sociologists and social psychologists have shown that, as the most overt kinds of prejudice and discrimination have declined, less blatant (but no less insidious) forms of racial and gender bias have emerged (Bonilla-Silva and Dietrich 2011; Correll 2017; Roscigno 2007). Prejudice has come to be expressed in the context of everyday interactions in increasingly subtle, covert, or symbolic ways, sometimes even in the absence of conscious discriminatory intent (Quillian 2006; see also Greenwald and Banaji 1995). As a result, discrimination in contemporary labor markets often takes indirect and elusive forms, such as heavy reliance on "soft skills" and "fit" in evaluations in a way that leads to social closure along racial or gender lines (Light, Roscigno, and Kalev 2011; Moss and Tilly 2001; Rivera 2016, 2020; Turco 2010). Employers who engage in such discrimination rarely endorse openly racist or sexist beliefs; rather, they tend to invoke meritocratic principles or the existence of supposedly race- and gender-blind policies to justify discriminatory actions (Light et al. 2011).

A related stream of sociological work focuses on the role that status beliefs and stereotypes play in contemporary forms of inequality (Berger et al. 1977; see Rivera 2020). This line of research shows that status beliefs and stereotypes about particular demographic groups subtly but powerfully shape how employers evaluate workers and how they distribute material, social, and symbolic rewards among them (e.g., Gorman 2005; Pedulla 2014; Quadlin 2018; Ridgeway 2001, 2011; Rivera and Tilcsik 2016, 2019). When employers treat ascriptive group membership as a proxy for the likely quality of workers, bias easily creeps into their evaluations because their perceptions of different groups reflect cultural beliefs that are often inaccurate and resistant to change, even in the face of disconfirming evidence (Pager and Karafin 2009; Ridgeway 2011). These perceptions of group differences, in turn, continue to be reinforced as people enact existing status inequalities in the context of everyday interactions (Ridgeway 1997; Ridgeway and Smith-Lovin 1999). It is not simply that some employers engage in intentional discrimination; rather, it is that the very definitions of competence and worth that employers use are shaped by broader societal forces and are biased against certain groups (see Rivera 2020).

A distinctively sociological insight into discrimination is that it can occur even if no particular individual makes a decision to treat people of different backgrounds differently (Small and Pager 2020). Since the 1970s, as Dobbin (2001:847-48) put it, "in place of the common-sense notion that discrimination is an outcome of managerial prejudice, there rose the idea that social structures can have discriminatory effects, whether by design or not." Accordingly, much sociological work has elaborated various institutional, organizational, and legal mechanisms of discrimination (e.g., Massey and Denton 1993; Pager and Shepherd 2008; Petersen and Saporta 2004; Ray 2019). For example, if the recruitment practices of a racially homogeneous organization heavily rely on referral networks - which tend to be racially homophilous - then those practices might systematically exclude job-seekers of a different race even if the people who implement the recruitment procedures are not themselves racially prejudiced (Small and Pager 2020). Such forms of structural discrimination can simultaneously occur in multiple, reciprocally related social domains — such as employment, education, and housing — that 
together form an integrated system of discrimination (Reskin 2012; see also Ridgeway and Correll 2004).

\section{The Idea of Statistical Discrimination}

Economic research on discrimination has followed a very different trajectory, starting with Gary Becker's pioneering book The Economics of Discrimination (1957). In Becker's model, some employers simply have a "taste for discrimination"_-or, in other words, a distaste for hiring members of certain groups. Thus, discrimination comes directly from employers' preferences; animus is a part of some employers' utility functions (Charles and Guryan 2016). These employers may decline to hire members of certain groups or, if they do hire them, they may offer them lower wages for identical productivity. By restricting the pool of their potential workers, discriminatory employers might earn lower profits and could be competed out of business by their non-discriminating peers, ultimately causing taste-based discrimination to disappear (Bertrand and Duflo 2016; England 1994; Pager 2016).

In the 1970s, the theory of statistical discrimination emerged as an alternative to the taste-based model (Aigner and Cain 1977; Arrow 1973; Phelps 1972). Unlike taste-based discrimination, statistical discrimination can occur even in the absence of any animus. Rather than emphasizing preferences as the driver of discrimination, this model is built on the premise that employers cannot perfectly assess the future productivity of prospective hires and thus use group membership as a proxy for productivity-related characteristics. Employers, in other words, rely on their overall beliefs about a group to make decisions about particular individuals from that group. Economists view statistical discrimination as a "rational response of firms to uncertainty about an individual's productivity” (Lundberg and Startz 1983:340).

In the most common version of the model, employers use observable group membership as a proxy for unobservable skills and rely on their beliefs about correlates of productivity, particularly their estimates of group differences in average productivity. In this case, employers use expected differences in group averages to fill in missing information about individual productivity (Aigner and Cain 1977; Arrow 1973; Bielby and Baron 1986; Phelps 1972). Other variants of the theory focus on cases when employers act not on the expectation that there are group differences in average productivity, but rather based on the belief that the variance in productivity is larger for some groups than for others, or the belief that groups differ in the degree of accuracy with which employers can assess the productivity of group members (Aigner and Cain 1977; Cornell and Welch 1996; Correll and Benard 2006; Lundberg and Startz 1983; Phelps 1972). In these cases, risk-averse employers facing imperfect information might discriminate against groups with larger expected variances in productivity and groups for which they expect employee screening to be less accurate (see England 1994).

The model of statistical discrimination appeals to economists for at least two reasons. One is that it helps explain the persistence of discrimination. Competition is expected to drive out tastebased discrimination, but statistical discrimination can survive under the same conditions and thus can explain why discrimination might occur even in competitive labor markets (Correll and Benard 2006; England 1994). Statistical discrimination theory also appeals to economists' formal modeling sensibilities. As Bertrand and Duflo (2016:311) point out, economists regard statistical discrimination as a "more disciplined explanation" than the taste-based model, because the former "does not involve an ad hoc (even if intuitive) addition to the utility function (animus toward certain groups) to help rationalize a puzzling behavior."

The idea of statistical discrimination has potential appeal and influence beyond academic economics as well. As discussed earlier, prior work suggests economic ideas are more likely to influence behavior if (a) they offer relatively clear and specific behavioral lessons, and (b) their 
practical implications are consistent with prevailing cultural beliefs, norms, and values. Fulfilling the first condition means people have a clear understanding of the practical implications of a theory; meeting the second facilitates the acceptance of those implications as appropriate. As I will discuss, statistical discrimination theory can satisfy both these conditions and is more likely to do so than the taste-based model.

The implications of statistical discrimination theory for employers are quite clear: it makes sense to use all available information about job applicants, including any easily observable group-level characteristics. The theory, in other words, offers a straightforward lesson: if a group-level characteristic seems to be a useful additional source of information about productivity, then it makes sense to use it in hiring decisions. The taste-based model, in contrast, offers implications with less clarity. Utility-maximizing employers should, of course, act according to their preferences, but the model also warns that if those preferences are biased, then decision-makers may be competed out of business. This is a less clear-cut lesson than the straightforward decision rule suggested by statistical discrimination theory.

Of course, even if a theory offers clear practical lessons, it might have little influence if it is at odds with important aspects of the broader cultural context. Statistical discrimination theory, however, is likely to have some resonance and normative acceptability, at least in Western cultural contexts, for three reasons.

First, consistent with the notion of purposive instrumental rationality-a central organizing principle of the modern Western worldview and understanding of economic life (Dobbin 1994a; Meyer and Rowan 1977) - the theory emphasizes that statistical discrimination is a rational, profit-maximizing, incentive-driven decision. The model depicts discrimination as the solution to a market imperfection (i.e., the lack of full information) and highlights the cognitive and economic utility of statistical discrimination (Correll and Benard 2006; Pager and Karafin 2009). For example, in Autor's (2009:19) description of the model, employers have an "incentive to use easily observable characteristics such as race or gender to infer the expected productivity of applicants," and they "make educated guesses" on the basis of those characteristics. As a result, statistical discrimination is "efficient" and "profit-maximizing" and represents "the optimal solution to an information extraction problem" (Autor 2009:23). In Bertrand and Duflo's (2016:311) words, "As a profit-maximizing prospective employer ... tries to infer the characteristics of a person ... they use all the information available to them. When the person-specific information is limited, group-specific membership may provide additional valuable information about expected productivity." Indeed, these perspectives suggest it might be irrational not to engage in statistical discrimination. As the lecture notes of an undergraduate labor economics course put it, "If group differences are real, and it is costly to judge case-bycase, then people who don't discriminate lose money" (Caplan n.d.:6).

The word "statistical" in the name of the theory reinforces the image of discrimination as a rational, calculated decision, even though the model does not presuppose that employers' beliefs about group differences are rooted in statistical data or any other type of systematic evidence. Employers' beliefs might be based on idiosyncratic observations or mere assumptions; in fact, they can be either accurate or inaccurate, but the economics literature has paid limited attention to this distinction (Bohren et al. 2019; England and Lewin 1989; Pager and Karafin 2009) and tends to treat the possibility of "statistical discrimination with bad statistics" as a special case rather than the core of the theory. ${ }^{2}$ Thus, the imagery of statistics, rationality, efficiency, incentives, and profit maximization tends to dominate descriptions of the model.

Second, in addition to emphasizing the rationality of statistical discrimination, some economists characterize the practice as fair and morally defensible. Consider this passage from the lecture notes of an economics course at MIT: 
Economists would generally say that employers "should" statistically discriminate because it is profit-maximizing, it is not motivated by animus, and it is arguably "fair" since it treats people with the same expected productivity identically (though not necessarily with the same actual productivity). Many economists might endorse statistical discrimination as good public policy. (Autor 2009:23)

Bertrand and Duflo (2016:312) make a similar argument:

While taste-based discrimination is clearly inefficient (simply consider how it constrains the allocation of talent), statistical discrimination is theoretically efficient and, hence, more easily defendable in ethical terms under the utilitarian argument. Moreover, statistical discrimination can also be argued to be "fair." .. . In fact, many economists would most likely support allowing statistical discrimination as a good policy, even where it is now illegal (as it is, e.g., in the US labor market and real-estate market contexts).

Even when not explicitly focusing on issues of ethics, economists emphasize that statistical discrimination does not stem from unethical or prejudiced intentions; statistically discriminating employers harbor no ill-will toward any group and are simply trying to hire the best workers at a given wage (Aigner and Cain 1977; Arrow 1973). Thus, although liberal political ideals do not normally permit the use of categorical differences (such as race and gender) as a principle of social ordering (Fourcade 2016), the rhetoric around statistical discrimination appears to circumvent this issue. It does so by implying that categorical differences are rooted in statistical considerations that rational employers take into account, and by suggesting that statistical discrimination is fair and neutral because it treats people with the same expected productivity identically.

Third, besides highlighting the rationality and ethical defensibility of statistical discrimination, economists often emphasize that it is ubiquitous and practically inevitable in many domains of life. Consider, for example, the following passages - the first from an introductory economics textbook and the second from a popular economics blog:

Let's say you are walking down a dark alley, late at night, in the warehouse district of your city. Suddenly, you hear footsteps behind you. You turn around and you see an old lady walking her dachshund. Do you breathe a sigh of relief? Probably. Would you breathe the same sigh of relief if you saw an angry young man in a dark leather jacket, muttering to himself? . . One way of reading this story is to claim that you are discriminating against young men, relative to old ladies. . . Another way of describing this story is that you are using information rationally. An angry young man in a leather jacket is far more likely to mug you than is an old lady walking her dachshund. (Cowen and Tabarrok 2015:340-341)

Judging everyone as an individual is expensive, and relying on statistical generalizations is a cheap and effective alternative. You don't clutch your purse when you see a bunch of little old ladies approaching on a deserted street. You don't offer a policeman a joint. You don't hire a guy with a mohawk as a receptionist at a law firm - even if he promises to get a haircut. Why not? Because on average, little old ladies don't commit violent crimes, policemen arrest people for possession of marijuana, and guys with mohawks have trouble with authority. (Caplan 2010)

The suggestion is that statistical discrimination is pervasive, inescapable, and normal. In the words of the author of the second passage, "No matter what they say, everyone engages in statistical discrimination" (Caplan 2010). Or, as the author of a popular economics book wrote, "Statistical discrimination is everywhere and affects almost everyone" (Oyer 2014:94).

Overall, by portraying statistical discrimination as economically rational, ethically defensible, and widely prevalent, these accounts might create a "descriptive and prescriptive expectation" 
(Miller 1999:1053) to rely on group-level generalizations, and they might provide a license and justification for doing so. In these accounts, generalizations about different social groups tend to be pictured not as crude proxies for individual characteristics, but instead as largely accurate statistical generalizations, which can confer a predictive advantage in many realms of life. Thus, the use of stereotypes is depicted as cognitively and economically useful as well as consistent with social norms, in the sense that "everyone is doing it." Consequently, I expect that exposure to the idea of statistical discrimination will strengthen people's belief in the validity, usefulness, and acceptability of relying on stereotypes and hence increase their likelihood of engaging in discrimination on the basis of ascriptive group characteristics.

This prediction is consistent with the insight that decision-makers tend to suppress their individual biases unless they can be justified on grounds other than prejudice, such as having assurances that their decisions are objective, rational, and fair (Castilla and Benard 2010; Crandall and Eshleman 2003). Thus, when employers feel confident that their decisions are impartial, rational, and ethically defensible, they feel more justified in relying on stereotypes and exert less effort to suppress their biases (Castilla and Benard 2010; Kunda and Spencer 2003).

The taste-based model is less likely to have such justificatory effects. First, statistical discrimination is described as an economically savvy approach, whereas the taste-based model implies that discrimination is bad for business because prejudiced employers are unlikely to survive competition. Second, economists sometimes defend statistical discrimination on ethical grounds, but they do not portray taste-based discrimination as fair or morally defensible. Third, statistical discrimination is depicted as a ubiquitous practice; in contrast, discriminatory tastes are often described as prejudices that only some employers harbor. Thus, taste-based discrimination lacks the justificatory basis that characterizes statistical discrimination.

Similarly, even statistical discrimination theory itself might become a less compelling frame if presented in a critical light that weakens these justifications. Some economists, for example, have recently pointed out that employers' beliefs about group averages may actually be mistaken, rather than accurate, even though the premise that statistical discrimination is efficient relies on the assumption that employers hold correct beliefs about group distributions (Bohren et al. 2019). Indeed, to emphasize the possibility of inaccurate beliefs, a few economists are now using the term "belief-based discrimination" instead of "statistical discrimination" (Bohren et al. 2019; Coffman, Exley, and Niederle forthcoming). Others have raised ethical objections, arguing that individuals have a right not to be discriminated against on the basis of group averages that may not hold true for them, especially if membership in the group is immutable and ascriptive (see Maitzen 1991; Phelps 1972; Starr 2014). And earlier research by economists suggests that statistical discrimination may become self-fulfilling if it leads members of negatively stereotyped groups to believe that investing in their skills will not be fully rewarded (Coate and Loury 1993; Lundberg and Startz 1983).

These issues, however, are seldom considered in popular distillations of the theory. For example, as reported in the online supplement (pages 2-3), I conducted a qualitative content analysis (Krippendorff 2004) of a randomly selected sample of 10 standard introductory economics textbooks - used in many college and Advanced Placement high school coursesand found little critical discussion of the theory. All textbooks framed statistical discrimination as rational, profit-maximizing behavior, and only a minority (four out of ten) included any critical commentary. Three textbooks noted that statistical discrimination could harm individuals who are in a stereotyped group but do not fit the stereotype. Only one textbook pointed out that employers might hold inaccurate beliefs about groups, and none of the texts mentioned self-fulfilling statistical discrimination. ${ }^{3}$ 
If presented more prominently, however, such critiques might weaken the justifications for statistical discrimination by raising doubts about its efficiency and fairness on the basis of insights that, like the idea of statistical discrimination itself, emerged within economics. Indeed, whether a theory is accompanied by credible critical perspectives can have major implications for its effects. For example, research shows that exposure to "sexual economics theory" - which posits that women exchange sex for men's resources-fostered a more hostile view of malefemale relationships, but reading a critique of the theory, which emphasized the importance of mutual affection to sexual intimacy, reduced this effect (Fetterolf and Rudman 2017).

Taken together, the above arguments suggest several predictions. First, exposure to statistical discrimination theory will increase people's belief in the validity and usefulness of stereotypes and their propensity to engage in discrimination based on ascriptive group membership. Second, this effect will not apply to all economic theories of discrimination; the taste-based model, in particular, is unlikely to have a similar effect, as it does not provide a compelling rationalization for discrimination and might, in fact, reinforce the belief that discrimination is neither rational nor acceptable. Third, the effect of statistical discrimination theory will be mitigated when the theory is presented alongside a critical commentary. The following hypotheses summarize these predictions:

Hypothesis 1: People exposed to statistical discrimination theory will show greater belief in the validity and usefulness of stereotypes than will people exposed to (a) the theory of taste-based discrimination, (b) neither theory, and (c) statistical discrimination theory alongside a critical commentary.

Hypothesis 2: People exposed to statistical discrimination theory will be more likely to engage in discrimination on the basis of ascriptive group characteristics than will people exposed to (a) the theory of taste-based discrimination, (b) neither theory, and (c) statistical discrimination theory alongside a critical commentary.

\section{METHODS}

It would be difficult to test these hypotheses with observational data, because correlations between exposure to statistical discrimination theory and a person's beliefs and behaviors may be due to selection (e.g., into studying economics) rather than treatment (Frank and Schulze 2000). To circumvent this issue, I conducted a survey experiment, randomly assigning exposure to the theory before examining participants' views and behavior.

Survey experiments are not without limitations. Participants' self-reported attitudes might diverge from their actual behaviors, and there is a risk of experimenter demand effects, whereby participants infer the purpose of the research and provide what they believe are the appropriate or desired answers (Zizzo 2010). In addition, survey experiments sometimes use participants whose experience is not directly relevant to the question at hand, such as undergraduates when the research questions concern managers' views and decisions.

I took several steps to mitigate these problems. First, I recruited participants with managerial experience, thus sampling from a theoretically relevant population. Second, I examined not only the stated attitudes of participants but also their behavior in a hiring simulation that gave them a financial incentive to hire the best-performing employees. Third, although recent research shows that survey experiments are much less vulnerable to experimenter demand effects than previously believed (Mummolo and Peterson 2019), I used several empirical design features that make survey experiments particularly robust to this issue (Zizzo 2010).

Participants in this experiment were randomly assigned to one of four conditions: (1) exposure to statistical discrimination theory, (2) no exposure to any theory of discrimination, (3) exposure 
to the taste-based model, or (4) exposure to statistical discrimination theory and a critical commentary. The first condition is the treatment. The second condition is nontreatment, a control group analogous to a natural history group in drug trials. The third condition is similar to a placebo control in that participants are exposed to an economic theory of discrimination, but it lacks the degree of prescriptive specificity and cultural acceptability that characterizes statistical discrimination theory. The last control condition is a variant of the treatment to test whether a critical commentary mitigates the treatment effect. Before conducting the experiment, I preregistered the hypotheses and the planned sample size, exclusion criteria, and analyses. ${ }^{4}$

\section{Stimulus Materials}

To create the stimulus materials - brief readings about statistical and taste-based discrimination - I started with a set of sources that non-academics tend to encounter: popular college textbooks (e.g., Cowen and Tabarrok 2015), instructors' lecture notes provided to students in economics courses (e.g., Autor 2009), popular press articles (e.g., Soffen 2016), economics blogs (e.g., Caplan 2010), business journals for managers (e.g., Li et al. 2017), economics books written for a general audience (e.g., Oyer 2014), and other accessible descriptions of taste-based and statistical discrimination (e.g., Bertrand and Duflo 2016).

Using these sources as models, I created a roughly 350-word summary of each theory. I also created a 150 -word critical commentary by summarizing some of the critical perspectives on statistical discrimination that have emerged within economics. To ensure the accuracy of these texts, I sought feedback from a labor economist and refined the materials accordingly. I then gathered feedback on the clarity of the materials from social scientists and business professionals and made additional changes. Finally, I conducted a pretest $(N=1,047)$ to ensure my stimulus materials were comparable to one another and to existing texts on the same topics (e.g., lecture notes and Wikipedia entries) on five dimensions: readability, believability, objectivity, extremity of stance, and neutrality of tone (Brescoll and LaFrance 2004). The pretests, described in the online supplement (pages 4-5), revealed no major differences (a) between the stimulus materials on statistical discrimination and taste-based discrimination or (b) between the stimulus materials and existing texts. The stimulus materials appear in the online supplement (pages 6-8).

The text about statistical discrimination reflected all three aspects that I argue can help make statistical discrimination theory more resonant - rationality, fairness, and ubiquity. However, to provide a conservative test of the hypotheses, the stimulus materials made these points less blatantly than did some of the actual economics texts. The experimental text, for example, noted that statistical discrimination is a "rational solution to a problem of imperfect information," but it did not say that employers who do not statistically discriminate will lose money. Similarly, it did not explicitly state that statistical discrimination was fair but simply highlighted that "statistical discrimination does not arise from bias, hostility, or dislike for a group." It also did not assert that "everyone" engages in statistical discrimination; rather, it provided examples to imply that statistical discrimination occurs in various hiring situations. ${ }^{5}$

\section{Participants}

I recruited participants from Prolific Academic (http://www.prolific.co), an online survey platform with a demographically diverse pool of more than 100,000 respondents. Research shows that Prolific is a source of high-quality experimental data (Palan and Schitter 2018). Compared to similar platforms, data from Prolific show a high level of internal reliability on psychometric scales, a low failure rate on attention checks, a high level of reproducibility of previously known effects, and low degrees of dishonest behavior by participants (Peer et al. 2017). Unlike MTurk respondents, Prolific participants have limited prior familiarity with 
common experimental research tasks and materials (Peer et al. 2017), which further contributes to data quality (see Chandler, Mueller, and Paolacci 2014; Chandler et al. 2015).

The sample was restricted to U.S. residents with managerial experience. I recruited 2,500 participants. Statistical power calculations indicated this sample size would be sufficient to detect effects similar in magnitude to those in prior studies on how exposure to textual materials affects attitudes (e.g., Brescoll and LaFrance 2004).

In some online survey platforms, recruitment materials or participant screening questions may inadvertently reveal the sampling criteria. This would be problematic in the current case, because some respondents might falsely indicate they have managerial experience if they realize that such experience is a prerequisite for participating in the study. Prolific avoids this issue by eliciting information about a large number of participant characteristics independent of any specific study (Palan and Schitter 2018); participants typically provide detailed demographic and socioeconomic information when they initially sign up to be included in the subject pool. Thus, prospective participants cannot tailor their pre-screening information to gain access to a particular study, and researchers can simply use Prolific's existing demographic or socioeconomic filters to target participants who fit their sampling criteria. ${ }^{6}$

\section{Mitigating Demand Effects}

As noted earlier, one important design consideration was to minimize experimenter demand effects - that is, changes in participant behavior due to cues about what constitutes appropriate behavior and what the experimenter expects or "demands" from participants (Orne 1962; Zizzo 2010). A particular concern is that participants may infer the goals of a study and respond in ways that help confirm the researcher's hypotheses.

Recent research, however, suggests online survey experiments are robust to demand effects (Mummolo and Peterson 2019). First, because online experiments involve depersonalized interactions between researchers and participants, the main source of demand effects - subtle cues that researchers give off in direct interactions - is eliminated. Second, participants only encounter a single cell in an experiment and do not know which sections of the survey are randomized, so they cannot easily infer the purpose of a study. Third, demand effects are most severe in the presence of "good subjects" who want to validate researcher expectations, and many online survey participants are indifferent to researcher intent. Accordingly, in a series of online experiments, Mummolo and Peterson (2019) failed to find evidence for demand effects, even when participants knew the hypotheses and had financial incentives to respond in line with them.

Nevertheless, it is possible to minimize demand effects even further. One approach is to use a between-subject design, which helps because participants have no information about the experimental cell in which they have been placed or the other conditions that exist in the study (Charness, Gneezy, and Kuhn 2012). Another solution is to use deception or obfuscation to make it difficult to infer the purpose of the research. If the experimental objectives remain obscure, participants are less likely to engage in actions that can act as a confounding factor (Zizzo 2010). Accordingly, I did the following: (1) implemented a between-subject design; (2) obfuscated the purpose of the research by creating an impression that the experimental manipulations and the sections measuring the dependent variables were separate and unrelated studies (see Brescoll and LaFrance 2004); and (3) included several filler materials and filler questions to make it more difficult to infer which questions I was interested in (Zizzo 2010).

Procedures 
Figure 1 provides an overview of the different parts of the experiment. Part 1 contained the experimental manipulations. Part 2 measured views about stereotypes and stereotyping. Part 3 captured participants' decisions in a hiring simulation. To conceal the specific purpose of the research from participants, each part was presented as a distinct, stand-alone survey with its own consent form and survey completion message, a different study description, and distinctive formatting (i.e., different font types, font sizes, color schemes, and design elements).

\section{<Figure 1 about here>}

The 2,500 respondents recruited for this research were told they would participate in two distinct surveys back-to-back: one on how people make sense of scientific ideas in the natural and social sciences (Part 1) and another on how people make decisions under uncertainty (Part

2). To further obfuscate the relationship between the different parts of the experiment, the hiring simulation (Part 3) was launched as an entirely distinct study one hour after participants had completed Parts 1 and 2.

Part 1. As a cover story, participants were told that the first survey focused on the public understanding of science and that they would be reading about two or three randomly selected topics drawn from a diverse set of natural and social sciences, including biology, chemistry, economics, geography, physics, psychology, and other fields. Participants were then given their first text, a filler reading about a topic from biology that was identical across conditions. Next, depending on their randomly assigned condition, participants read about a topic in economics: statistical discrimination, taste-based discrimination, or statistical discrimination with a critical commentary. Participants in the nontreatment condition did not see this part. All respondents then completed another filler reading, which focused on a topic in atmospheric science. Thus, the actual manipulation was sandwiched between two readings about unrelated concepts, and the two filler readings helped create an impression that the survey was about scientific topics more broadly. As a manipulation check, and to further boost the cover story, participants answered several multiple-choice comprehension questions about each reading. (The filler readings and comprehension checks appear on pages 9-10 of the online supplement.) Respondents were then asked to write down what they believed the purpose of the survey was.

Part 2. A new consent form marked the beginning of the second survey, which purportedly focused on decision-making under uncertainty. In this section, participants completed two questionnaires capturing their views on stereotyping and stereotypes as well as several filler questions, presented in a random order. The questionnaires and filler questions are listed in the online supplement (pages 11-12). Finally, participants answered questions about their gender, race, and age, as well as what they believed the purpose of the survey was. ${ }^{7}$

To measure belief in the acceptability of stereotyping, I used the pre-validated Acceptance of Stereotyping Questionnaire (Carter et al. 2006). Using seven-point Likert scales ( 1 = strongly disagree, 7 = strongly agree), subjects rated their agreement with 12 statements such as "Stereotypes are useful in daily life even though they are not always correct" and "Stereotypes have too much influence on our behavior toward others" (reverse coded) $(\alpha=.86)$. In the absence of a preexisting scale measuring the extent to which people believe stereotypes are accurate, I created a set of 12 items focused on the perceived accuracy of stereotypes, also rated on seven-point scales. ${ }^{8}$ Sample items included "On average, stereotypes tend to be true" and "Many stereotypes are based on belief rather than evidence" (reverse coded) $(\alpha=.93)$.

Part 3. One hour after completion of Parts 1 and 2, Part 3 was posted as what appeared to be a completely different study. Unbeknownst to potential respondents, only those who had participated in Parts 1 and 2 were invited to Part 3, which was described as a hiring simulation with an opportunity to earn a bonus. ${ }^{9}$ 
Participants first read a brief description of the Graduate Management Admission Test (GMAT), a computer-adaptive standardized exam that many graduate business programs require for admission. They then saw the following prompt (emphasis in the original):

We collected the profiles of 10 people who are applying to Master in Business Administration (MBA) programs and have recently taken the GMAT. The GMAT score ranges from 200 to 800 and measures performance on the quantitative and verbal sections together, as a single score. You will now act as an employer and have the opportunity to select 4 of these people to join your team. Your task is to pick a team of 4 so that the team members' total GMAT score is as high as possible. Your bonus will depend entirely on the combined GMAT score of the people you select for your team.

To further emphasize the incentivized nature of the decision, the instructions provided the formula for calculating the bonus payment as well as some examples to illustrate that the bonus would be directly proportional to the combined GMAT score of the four selected applicants. ${ }^{10}$

Next, participants were shown the profiles of 10 actual working professionals who had taken the GMAT to apply for Master in Business Administration (MBA) programs. The profiles were collected from Poets \& Quants, a popular business education website that regularly features real MBA applicants. ${ }^{11}$ Each profile included the applicant's first name, undergraduate institution, major, GPA, and a brief summary of work experience ("finance role at Target for three years"). No other information (e.g., last name, photograph, or GMAT score) was provided. The order of the profiles was randomized for each respondent. Because the first names signaled applicants' gender, it was possible to test whether, in line with Hypothesis 2, participants exposed to statistical discrimination theory engaged in more discrimination on the basis of an ascriptive characteristic. ${ }^{12}$ The profiles appear in the online supplement (pages 13-14).

Participants indicated which four of the 10 applicants they decided to hire. After completing the survey, they were asked to write down what they believed the purpose of the study was. They then received their basic compensation for participation and a bonus that was determined on the basis of the actual GMAT scores of the applicants they had selected. Once all participants in Part 3 had submitted their answers, the study was closed, and all respondents received a debriefing message through their Prolific accounts.

Although the hiring task in Part 3 was highly stylized, it had several appealing features. First, as in an actual résumé-screening situation, decision-makers knew the educational and work histories of applicants but could not perfectly determine how well they would perform on the task at hand (i.e., the GMAT). Second, rather than simply participating in a guessing game with no stakes, employers had an incentive to select applicants with the highest expected performance. Third, given that the profiles belonged to real MBA applicants whose GMAT scores I knew, I was able to examine whether exposure to statistical discrimination theory led to better decisions from a purely economic perspective. This is a helpful feature because a skeptic might argue that learning about the theory might simply result in a more rational approach to hiring by encouraging people to use all available information. I was able to explore this possibility by examining whether participants in the treatment group hired teams with higher GMAT scores (and thus earned higher bonuses) than did participants in the control groups.

\section{RESULTS}

Following the preregistered analysis plan, the analytic sample included only those participants who correctly identified the principal features of the theory of discrimination they read. Thus, respondents who failed any of the comprehension check questions $(n=251$, or 10 percent) were 
dropped, resulting in a sample of 2,249 participants in Parts 1 and 2. Of these respondents, 73 percent $(n=1,645)$ agreed to participate in the hiring simulation (Part 3) as well.

Table 1 displays demographic information for the sample in Parts 1 and 2 and the subset of participants who also completed Part 3. There were no significant differences between Part 3 subjects and those who completed only Parts 1 and $2 .{ }^{13}$ Open-ended responses at the end of each part suggest that fewer than 1 percent of participants correctly identified the purpose of the research or suspected the different parts of the experiment were related; excluding these participants from the analysis did not materially affect the conclusions. ${ }^{14}$

\section{$<$ Table 1 about here>}

Table 2 displays means, standard deviations, and differences in means across conditions for the three dependent variables. As Table 2 shows, consistent with the first hypothesis, participants exposed to statistical discrimination theory (without a critical commentary) perceived stereotyping as more acceptable and stereotypes as more accurate than did participants in the control groups. Consistent with the second hypothesis, participants in the treatment group also selected fewer women for their teams in the hiring simulation. Overall, exposure to statistical discrimination theory had the predicted attitudinal and behavioral effects, and the inclusion of a critical commentary mitigated these effects.

\section{<Table 2 about here>}

The estimated size of these effects is non-trivial. Exposure to statistical discrimination theory led to a one-third standard deviation increase in both the acceptance of stereotyping and the perceived accuracy of stereotypes relative to nontreatment and the placebo (taste-based) condition. It also led to a one-fifth standard deviation increase in both attitudinal variables relative to the critical commentary condition. There was a substantively significant effect in the hiring simulation as well. On average, participants in the control groups included two women in their teams of four; in contrast, those in the treatment group selected only 1.8 women. This is a substantial difference, because it implies that exposure to statistical discrimination theory shifted the average outcome from gender balance to a gender gap of about 10 percentage points, with 55 percent men versus 45 percent women included on an average team.

Although not hypothesized, an additional pattern worth noting is that the perceived accuracy of stereotypes was lowest in the taste-based condition. This finding may partly reflect the fact that the taste-based model emphasizes the biased and inefficient nature of discrimination.

To complement these results, Table 3 presents regression models, which have an added benefit of revealing correlations between participant characteristics and the dependent variables. In these models, the omitted reference category for the experimental conditions is exposure to statistical discrimination theory. The first two models are OLS regressions; the third model is a Poisson regression because the dependent variable, the number of women each participant hired, is a count. Consistent with the hypotheses, these models show that exposure to the idea of statistical discrimination led to greater acceptance of stereotyping, greater perceived accuracy of stereotypes, and the selection of fewer women than did the three control conditions. ${ }^{15}$

\section{$<$ Table 3 about here>}

These models also reveal differences by participant characteristics. Female participants and those who did not identify as either male or female were, on average, less convinced of the acceptability and accuracy of stereotypes than were male respondents. Likewise, Black respondents expressed less agreement with these items than did White participants. Both of 
these patterns are consistent with prior research (Carter et al. 2006). In addition, female participants and those who did not identify as either male or female tended to select more women for their teams than did male respondents. In a series of additional analyses, I explored possible heterogeneity in the effect of exposure to statistical discrimination theory by participant gender, race, and age, but I did not find significant interaction effects consistent with such heterogeneity.

Next, I examined the extent to which changes in the attitudinal dependent variablesacceptance of stereotyping and perceived accuracy of stereotypes - explained (i.e., mediated) the effect of statistical discrimination theory on participants' decisions during the hiring simulation. To do so, I used structural equation modeling to decompose the direct and indirect effects of exposure to statistical discrimination theory on the number of women hired. Figure 2 and Table 4 summarize the results of this analysis. As the paths in Figure 2 show, exposure to statistical discrimination theory had both a direct effect on the number of women hired and an indirect (mediated) effect that operated through the acceptance of stereotyping and the perceived accuracy of stereotypes. Table 4 calculates the relative importance of the direct and indirect effects and indicates that the majority of the treatment effect on hiring decisions-nearly 60 percent - was mediated by the attitudinal variables.

\section{$<$ Figure 2 about here>}

$<$ Table 4 about here>

\section{Alternative Explanations}

I considered several alternative explanations. First, to further probe the observed effects of statistical discrimination theory on the acceptance of stereotyping and the perceived accuracy of stereotypes, Table 5 shows the number of times each response category (e.g., "strongly disagree") was selected by an average participant in the treatment group versus the control groups. Psychometric research shows respondents may select the middle category of a Likert scale ("neither agree nor disagree") not only when they want to express a moderate view but also when they are uncertain or undecided or have a conditional ("it depends") response (e.g., Kulas and Stachowski 2009). Thus, it is important to examine whether the observed treatment effect indeed reflects greater agreement with the acceptability and accuracy of stereotypes or simply greater uncertainty about these issues.

\section{$<$ Table 5 about here>}

The last column in Table 5 sheds light on this question. One clear pattern is that exposure to statistical discrimination theory led to a decrease in the number of "strongly disagree" and "disagree" responses on both scales. Another important pattern is that, although the number of "neither agree nor disagree" responses did go up in the treatment condition, the largest increase was in the "somewhat agree" category, and the number of "agree" responses also increased. This finding suggests exposure to statistical discrimination theory did indeed increase the extent to which participants viewed stereotypes as accurate and acceptable rather than simply increasing uncertainty about the accuracy and acceptability of stereotypes. ${ }^{16}$ As an additional test, I re-examined the data while excluding 261 participants who answered "neither agree nor disagree" to at least half the items on either scale. In essence, this analysis treated participants who frequently selected the middle category on the Likert scales as having provided missing or non-substantive answers. Even after excluding these participants, the treatment effect remained significant and similar in magnitude to what I observed in the main analysis. ${ }^{17}$ This result, too, suggests the effect of statistical discrimination theory was not simply driven by increased uncertainty expressed in "neither agree nor disagree" responses; rather, there was a genuine shift toward greater agreement with the acceptability and accuracy of stereotypes. 
Another alternative explanation concerns the results of the hiring simulation. According to this argument, exposure to statistical discrimination theory might cause participants to pay more attention to certain human capital factors that, within this particular pool of candidates, correlate with gender. For example, among the candidates in the hiring simulation, slightly more men than women had a business or economics degree. If participants exposed to statistical discrimination theory came to view such a degree as more valuable or relevant than did those in the control groups, then the results might simply be capturing a greater valuation of business and economics degrees, rather than increased discrimination against women.

For this concern to be valid, however, the supposed confounding factor (e.g., a preference for business and economics degrees) would need to be correlated with exposure to statistical discrimination theory. To examine this possibility, I performed ANOVA tests with dependent variables capturing various characteristics of the teams that participants selected: average GPA; average ranking of undergraduate institution (by U.S. News \& World Report); and the number of workers with (a) business or economics degrees, (b) engineering degrees, (c) finance experience, (d) management experience, (e) data analytics experience, and (f) experience at a major firm. I found no significant differences in any of these variables among the conditions. These human capital factors, in other words, were uncorrelated with experimental treatment and thus could not act as a confound. As an additional test, I included these factors in Poisson models predicting the number of women hired; the estimated treatment effect remained robust. ${ }^{18}$

Finally, I explored whether exposure to the idea of statistical discrimination led to more rational decisions from a purely economic perspective in the hiring simulation. To do so, I examined whether participants in the treatment group selected teams of candidates with higher GMAT scores (and thus earned higher bonuses) than did participants in the other conditions. The mean team-level GMAT score was $2,893(\mathrm{SD}=43.8)$ in the statistical discrimination condition, 2,887 $(\mathrm{SD}=44.6)$ in the nontreatment condition, 2,894 $(\mathrm{SD}=42.2)$ in the taste-based discrimination condition, and 2,889 ( $\mathrm{SD}=45.4)$ in the critical commentary condition. I could not reject the null hypothesis that the means were equal across the four conditions.

\section{DISCUSSION}

\section{The Influence of Statistical Discrimination Theory}

Discrimination in labor markets and the workplace has been of central concern to sociologists and other social scientists for quite some time. A vast and continually growing literature aims to identify which theory of discrimination is most consistent with empirical patterns observed in labor markets and a wide range of other social domains (e.g., Altonji and Pierret 2001; Ewens, Tomlin, and Wang 2013; Fernandez and Greenberg 2013; Guryan and Charles 2013).

At the same time, in trying to adjudicate between competing theories, scholars of discrimination have rarely turned their analytic gaze to the potential influence of the theories themselves, even though models of discrimination are often imbued with normative viewpoints and behavioral expectations regarding how rational decision-makers act. In this article, I argued that these theories not only describe or explain discrimination, but they might also affect the extent to which people view discrimination as rational and acceptable. Thus, rather than merely explaining discrimination, they can affect decision-makers' propensity to engage in it.

Ferraro and colleagues (2009:673) argued that social scientists "need to take responsibility for the consequences of what we teach and write, something already long discussed in medicine in the field of bioethics" and called for "studies of the effects of exposure to ... various theories on values and behavior." The present article answers that call by focusing on one of the most 
prominent social scientific models of discrimination, a theory whose influence extends from classrooms to courtrooms and from the popular press to policy debates.

The first main finding of this research is that exposure to the idea of statistical discrimination strengthened people's belief in the accuracy of stereotypes, their acceptance of stereotyping, and the extent to which they engaged in gender discrimination in a hiring simulation. This result suggests that, rather than being a neutral conceptual framework, statistical discrimination theory might rationalize, justify, and elicit discriminatory decisions. This finding, of course, does not imply that the theory of statistical discrimination lacks empirical validity; indeed, numerous studies provide compelling evidence in alignment with the predictions of the theory in contemporary labor markets and other domains (e.g., Altonji and Pierret 2001; Fernandez and Greenberg 2013; Rissing and Castilla 2014). What this finding does imply, however, is that the theory of statistical discrimination does more than simply explain reality; it has consequences for how people view discrimination and whether they engage in it.

The second key finding is that providing a brief critical commentary after presenting statistical discrimination theory mitigated the effects outlined above. The commentary given to participants made three points: (1) statistical discrimination implies that individuals may be judged on the basis of group averages rather than their individual merit; (2) a statistically discriminating employer's beliefs may be inaccurate; and (3) statistical discrimination based on inaccurate beliefs may become self-fulfilling. None of these points is a radical or controversial criticism of the theory. The first point is implied by standard models of statistical

discrimination, and the second and third points, too, have been raised by economists, rather than originating from outside the discipline. And yet, these simple caveats alleviated the effects of exposure to statistical discrimination theory. The broader implication is that a given theory may have very different effects depending on how it is framed and presented. Theories of discrimination can not only rationalize but also challenge the rationality of stereotypes and discrimination.

Caveats like the ones included in the critical commentary in this experiment are not hard to come by in the literature on statistical discrimination. As is often the case, the scholarly literature is much more nuanced than the version of the theory that appears in textbooks, media accounts, and policy debates. For example, both pioneers of the concept of statistical discrimination-Arrow and Phelps - have acknowledged it is just one of the several mechanisms of discrimination. As Phelps (1972:661) put it, "I do not know (nor claim to know) whether in fact most discrimination is of the statistical kind. But what if it were? Discrimination is no less damaging to its victims for being statistical." The theory has continued to evolve in recent years, with some scholars noting the self-fulfilling nature of statistical discrimination and others suggesting a more suitable name might be "belief-based discrimination" (Bohren et al. 2019; Coffman et al. forthcoming). However, popular depictions of the theory are less nuanced and, as this research shows, might have unintended effects on how people think and make decisions.

\section{The Rhetoric of Rational Discrimination}

Economist Deirdre McCloskey called attention to the "literary character of economics" (1984:97) and noted that "economists are tellers of stories ... and from recognizing this we can know better what economists do" (1990:5). Consistent with this insight, this article's exploration of the arguments, assumptions, and terminology associated with statistical discrimination theory sheds some light on the rhetorical techniques that help frame discrimination as economically useful and morally palatable. These techniques include (a) sidestepping the issue of whether a discriminator's beliefs are accurate or not; (b) emphasizing the statistical (rather than belief-based) nature of discrimination; (c) stressing that statistical 
discrimination involves no ill-will toward any group or individual; and (d) asserting the fairness of treating people with the same expected (although not actual) productivity identically.

Yet another technique used to rationalize statistical discrimination involves emphasizing the similarity of profoundly different decision situations - for example, an employer's decision about which job candidates to hire and an individual's decision about what to do when hearing footsteps in a dark alley and seeing either a young man in a leather jacket angrily muttering to himself or an old lady walking her dachshund. Although the employment decision and the dark alley scenario are depicted as analogous, there are crucial differences between them. An employer going through a stack of résumés is in a vastly more powerful position than someone who is alone in a dark alley. The employer also has much more time to weigh the decision and seek more information. And the observable characteristics of the target person are fundamentally different between these situations. Whereas being Black or female is an ascribed status, wearing a leather jacket and angrily muttering to oneself are more achieved than ascribed. But textbook depictions of statistical discrimination focus on similarities across these situations, emphasizing the possibility of using observable group-level characteristics to make a sound decision in both cases. And because it seems natural to statistically discriminate in the dark alley case, the suggestion is that it is also acceptable to do so in a hiring situation.

These rhetorical techniques help convey the normative viewpoints and descriptive and prescriptive expectations with which statistical discrimination theory is imbued. Prior research shows that many people attempt to suppress their biases unless they can be justified on grounds other than prejudice, such as objectivity, rationality, and fairness (Castilla and Benard 2010; Crandall and Eshleman 2003; Kunda and Spencer 2003). The rhetoric of statistical discrimination, much like the rhetoric of meritocracy (Castilla and Benard 2010), seems to provide such justification, making people less motivated to avoid relying on stereotypes. Although a comprehensive textual analysis was beyond the scope of this research, this article highlights potential avenues for future scholarship to explore the rhetorical strategies of different theories of discrimination and inequality and examine how these supposedly value-free models, and their popular depictions, communicate normative content.

More broadly, this research suggests new lines of inquiry for the sociology of morality. Sociologists have recently called for a renewed interest in the study of morality, noting that sociology can make a critical contribution to understanding morality as a dependent variable by illuminating the social processes that create particular moral conceptions (e.g., Hitlin and Vaisey 2013; Stets and Carter 2012). This article sheds light on an often-overlooked but potentially influential factor shaping those processes: social science theories that are supposedly neutral and amoral but nevertheless frame some behaviors as more ethically defensible than others.

An emerging literature on actuarial fairness and algorithmic prediction, for example, shows that an intense public and regulatory debate in many domains - from insurance pricing to child welfare decisions to criminal sentencing - concerns the conditions under which predictive data are fair to use and the kinds of categories that should and should not be included in such data (Fourcade and Healy 2013, 2017; Hirschman and Bosk 2020; Kiviat 2019; Starr 2014). In essence, these debates are about statistical discrimination - and whether and when it is morally and legally acceptable. As predictive analytics increasingly permeate markets (Kiviat 2019) and the language of economics increasingly permeates public policy (Hirschman and Berman 2014), the idea of statistical discrimination will likely play a critical role in such debates.

\section{Economic Theories and Economic Behavior}


Sociologists have long been interested in the effect of social theories on behavior, and the influence of economic ideas and models has attracted particularly widespread interest in recent years (Blyth 2002; Dobbin and Jung 2010; Ferraro et al. 2005; Fourcade 2009; Jung and Dobbin 2016; Mackenzie 2008). At the same time, scholars note that it would be naïve to expect all or even most economic theories to have practical influence on decisions and behaviors. Consistent with this view, the taste-based model of discrimination did not have the same effects as statistical discrimination theory, even though the two models share common disciplinary origins and attempt to explain the same outcome. Building on prior work (Brisset 2016; Ferraro et al. 2005; Mirowski and Nik-Khah 2007; Schudson 1989), I argued that the factors behind this divergence likely include the lack of specific behavioral implications of the taste-based model and the greater cultural resonance and moral palatability of statistical discrimination.

The goal of this article was to develop and test predictions about the effects of an important theory of discrimination. Thus, I examined statistical discrimination theory as a complete bundle of different rhetorical elements rather than trying to pin down which specific aspects of the theory contribute most to its influence. It was also not my intent to develop a general theory of why some social theories are more likely to be influential than others. A promising avenue for future research, however, is to directly and more generally examine and elaborate the factorsincluding prescriptive specificity and cultural resonance-that explain why some theories and models have practical influence and others do not.

Overall, this article draws attention to the impact of social scientific theories of discrimination and suggests a sociological perspective - which treats theories not as neutral representations of phenomena but rather as premises imbued with normative viewpoints and behavioral implications - is essential in understanding this impact. Theories of discrimination can complicate and exacerbate patterns of inequality by shaping how people exposed to those theories think, what they do, and what they think they are doing. What we write and teach about discrimination matters, sometimes in unintended, unexpected, and unexamined ways.

\section{Acknowledgments}

I am grateful to the Institute for Gender and the Economy at the Rotman School of Management for its generous financial and intellectual support. I wish to thank Kwangjun An, Anne Bowers, Clayton Childress, Lisa Cohen, Matthew Corritore, Diana Dakhlallah, Daphne Demetry, Stefan Dimitriadis, Laura Doering, Alicia Eads, Sarah Kaplan, Arvind Karunakaran, Sida Liu, Elena Obukhova, Kim Pernell-Gallagher, Ryann Manning, Lauren Rivera, Sameer Srivastava, and the Toronto Group of Seven, as well as seminar participants at McGill University, York University, and the University of Toronto for helpful feedback on earlier drafts.

\section{Notes}

1. For a few examples of statistical discrimination theory in the popular and business press, policy papers, and economics books intended for a general or managerial audience, see Bohnet (2016), Harford (2008), Hindlian and colleagues (2018), Krueger (2002), Leins (2019), Li, Zhang, and Cui (2017), Oyer (2014), Soffen (2016), and The Economist (2014). For a qualitative content analysis of how statistical discrimination is covered in 10 standard introductory economics textbooks, see pages $2-3$ of the online supplement.

2. Traditionally, the assumption has been that, because a critical task of employers is to assess worker productivity, "employers . . . inefficient in this function will tend to be weeded out by the 'market mechanism' of competition" (Aigner and Cain 1977:177). This perspective implies that employers will not persist in believing that members of a group are, on average, more productive than members of another group if the group means are, in fact, equal. If employers held that erroneous belief, they would mistakenly overpay one of the groups, and such behavior is unlikely to persist in competitive markets (Aigner and Cain 1977). 
3. In part, the lack of focus on these issues in textbooks reflects patterns in the scholarly literature. For example, a review of more than 100 empirical papers on discrimination published in top economics journals found that only one in ten articles on statistical discrimination considered the possibility of inaccurate employer beliefs (Bohren et al. 2019).

4. The preregistration document is available at https://aspredicted.org/n26r8.pdf.

5. In some vignette experiments, the goal is to isolate the effect of one specific word or statement. Here, in contrast, the goal was to examine the effect of statistical discrimination theory as a complete bundle of arguments and assumptions. This approach is similar, for example, to that of recent research exploring the effect of exposure to information about economic inequality in the United States versus exposure to a control article of similar length and format but focusing on baseball—a neutral and entirely different topic (McCall et al. 2017).

6. As an additional safeguard, members of the subject pool are not made aware of the sampling criteria of any particular study, and Prolific shows them information only about the surveys in which they are eligible to participate. To further minimize the risk that participants might misrepresent their characteristics to gain access to a study, respondents can only make changes to their demographic information after all studies that are active on the platform at the time of initiating the change have been completed. In addition, Prolific actively verifies respondents' country of residence using their phone information.

7. Participants in Parts 1 and 2 were paid for their time following Prolific's guidelines; they received $\$ 3$ for roughly six minutes, corresponding to a $\$ 30 /$ hour wage, which is substantially higher than compensation in many survey experimental studies that use participants from the general population.

8. To develop this scale, I created an initial pool of 20 items, informed by the literature on stereotype accuracy (e.g., Ryan 2003). To select the most appropriate items, I conducted cognitive interviews with 10 business professionals and four researchers with expertise on stereotypes. Based on the interviews, I dropped eight items for lack of clarity and modified the wording of several retained items. I then ran a pretest with the remaining 12 items using a sample of 250 college-educated U.S. residents. The pretest results indicated high internal consistency and satisfactory inter-item and item-rest correlations for these items.

9. To recruit participants for Part 3, I used Prolific's "whitelist" screener, which allows a researcher to designate a list of respondents to be invited to a survey and thus resample participants from previous studies. Participants do not know whether they were invited to a survey based on a whitelist. The retention rate across surveys that use this tool to re-target participants tends to be high (Palan and Schitter 2018), especially when the time between the different surveys is short, as it was in this case.

10. Roughly similar in magnitude to performance-based pay typically used in experimental economics research on discrimination, the theoretical range for the bonus (given beyond the basic compensation of $\$ 3$ ) ranged from $\$ .50$ to $\$ 2$, which corresponds to a $\$ 5$ to $\$ 20$ increase in projected hourly compensation.

11. Before launching the study, I downloaded the 10 most recent profiles for which complete information (GMAT score, educational and work history, gender) was available. Because study participants were based in the United States, I excluded profiles with non-U.S. undergraduate degrees. The resulting set of profiles was quite racially homogenous (mostly White), so I focused on gender as the ascriptive characteristic on which the profiles varied. 
12. To each profile, I assigned a name that reflected the actual candidate's gender, such that all names were similar in perceived age, warmth, and competence. To select names, I used the results of recent large-scale surveys on the perception of common first names in the United States (Newman et al. 2018).

13. In addition, a logit model predicting participation in Part 3 showed that neither participant demographics, nor the experimental condition assigned in Part 1, nor participants' survey responses in Part 2 were significant predictors of the likelihood of completing Part 3.

14. Participants' descriptions of the perceived purpose of the research revealed that, unsurprisingly, most respondents correctly inferred that Part 2 was about stereotypes; however, fewer than 1 percent guessed that Parts 1 and 2 were related and that the goal of the research was to examine the effect of materials in Part 1 on responses in Part 2. No respondent indicated inferring a relationship between Part 3 and the other two parts.

15. For ease of interpretation of the Poisson model in Table 3, I calculated average marginal effects. The model implies that, on average, other things equal, people exposed to statistical discrimination theory selected (a) .19 fewer women than did participants in the nontreatment condition, (b) .20 fewer women than did participants in the taste-based condition, and (c) .16 fewer women than did participants in the critical commentary condition.

16. Disaggregating the various control conditions did not substantively change the conclusions about these patterns.

17. Even when excluding these participants, acceptance of stereotyping was greater in the treatment group (mean $=3.62, \mathrm{SD}=.99)$ than in the control groups (mean $=3.34, \mathrm{SD}=.99$ ), and stereotypes were still perceived as more accurate in the treatment group (mean $=3.53, \mathrm{SD}=$ 1.11) compared to the control groups (mean $=3.26, \mathrm{SD}=1.10)$.

18. As yet another approach, I created a candidate-level dataset in which each row recorded a candidate's gender, human capital indicators, and the condition to which the evaluator was assigned. I then ran a logit model with a dependent variable indicating whether a candidate was selected. I controlled for GPA; university ranking; type of major; experience in finance, management, and data analytics; and experience at a major firm. According to this model, too, female applicants were less likely to be selected if the evaluator had been exposed to statistical discrimination theory.

References

Aigner, Dennis J., and Glen G. Cain. 1977. "Statistical Theories of Discrimination in Labor Markets." Industrial and Labor Relations Review 30(2):175-87.

Altonji, Joseph G., and Charles R. Pierret. 2001. "Employer Learning and Statistical Discrimination." The Quarterly Journal of Economics 116(1):313-50.

Arrow, Kenneth. 1973. "The Theory of Discrimination.” Pp. 3-33 in Discrimination in Labor Markets, edited by O. Ashenfelter and A. Rees. Princeton, NJ: Princeton University Press.

Ashenfelter, Orley, and Ronald Oaxaca. 1987. "The Economics of Discrimination: Economists Enter the Courtroom." The American Economic Review 77(2):321-25.

Autor, David. 2003. "Lecture Note: The Economics of Discrimination — Theory." 
Autor, David. 2009. "Lecture Note: The Economics of Discrimination I."

Babb, Sarah. 2004. Managing Mexico: Economists from Nationalism to Neoliberalism. Princeton, NJ: Princeton University Press.

Baron, James N., and William T. Bielby. 1980. "Bringing the Firms Back in: Stratification, Segmentation, and the Organization of Work." American Sociological Review 45(5):737-65.

Becker, Gary. 1957. The Economics of Discrimination. Chicago: University of Chicago Press.

Berger, Joseph, M. Hamit Fişek, Robert Z. Norman, and Morris Zelditch Jr. 1977. Status Characteristics and Social Interaction: An Expectation States Approach. New York: Elsevier.

Berman, Elizabeth Popp. 2017. "From Economic to Social Regulation: How the Deregulatory Moment Strengthened Economists' Policy Position." History of Political Economy 49(Supplement):187-212.

Berman, Elizabeth Popp. Forthcoming. "The Preferences of Economists." In Thinking Like an Economist: How Economics Became the Language of U.S. Public Policy. Princeton, NJ: Princeton University Press.

Bertrand, Marianne, and Esther Duflo. 2016. Field Experiments on Discrimination. NBER Working Paper 22014. National Bureau of Economic Research.

Bielby, William T., and James N. Baron. 1986. "Men and Women at Work: Sex Segregation and Statistical Discrimination." American Journal of Sociology 91(4):759-99.

Blyth, Mark. 2002. Great Transformations: Economic Ideas and Institutional Change in the Twentieth Century. Cambridge, UK: Cambridge University Press.

Bohnet, Iris. 2016. What Works. Cambridge, MA: Harvard University Press.

Bohren, J. Aislinn, Kareem Haggag, Alex Imas, and Devin G. Pope. 2019. "Inaccurate Statistical Discrimination.” NBER Working Paper 25935. National Bureau of Economic Research, Chicago, IL.

Bonilla-Silva, Eduardo. 1997. "Rethinking Racism: Toward a Structural Interpretation." American Sociological Review 62(3):465-80.

Bonilla-Silva, Eduardo, and David Dietrich. 2011. "The Sweet Enchantment of Color-Blind Racism in Obamerica." The ANNALS of the American Academy of Political and Social Science 634(1):190-206.

Bracic, Ana. 2018. "For Better Science: The Benefits of Community Engagement in Research." PS: Political Science \& Politics 51(3):550-53.

Brescoll, Victoria, and Marianne LaFrance. 2004. "The Correlates and Consequences of Newspaper Reports of Research on Sex Differences.” Psychological Science 15(8):515-20.

Brisset, Nicolas. 2016. "Economics Is Not Always Performative: Some Limits for Performativity." Journal of Economic Methodology 23(2):160-84. 
Caplan, Bryan. 2010. "The Ethics and Etiquette of Statistical Discrimination." Econlib.

Retrieved November 3, 2019 (https://www.econlib.org/archives/2010/07/the_ethics_and.html).

Caplan, Bryan. n.d. "Weeks 12-13: Discrimination (Labor Economics Lecture Notes, George Mason University)."

Carter, Jason D., Judith A. Hall, Dana R. Carney, and Janelle C. Rosip. 2006. “Individual Differences in the Acceptance of Stereotyping." Journal of Research in Personality 40(6):110318.

Castilla, Emilio J. 2008. "Gender, Race, and Meritocracy in Organizational Careers." American Journal of Sociology 113(6):1479-526.

Castilla, Emilio J., and Stephen Benard. 2010. "The Paradox of Meritocracy in Organizations." Administrative Science Quarterly 55(4):543-676.

Chandler, Jesse, Pam Mueller, and Gabriele Paolacci. 2014. "Nonnaïveté among Amazon Mechanical Turk Workers: Consequences and Solutions for Behavioral Researchers." Behavior Research Methods 46:112-30.

Chandler, Jesse, Gabriele Paolacci, Eyal Peer, Pam Mueller, and Kate A. Ratliff. 2015. "Using Nonnaive Participants Can Reduce Effect Sizes.” Psychological Science 26(7):1131-39.

Charles, Kerwin Kofi, and Jonathan Guryan. 2011. "Studying Discrimination: Fundamental Challenges and Recent Progress." Annual Review of Economics 3(1):479-511.

Charles, Kerwin Kofi, and Jonathan Guryan. 2016. “Taste-Based Discrimination.” Pp. 1-8 in The New Palgrave Dictionary of Economics. London, UK: Palgrave Macmillan.

Charness, Gary, Uri Gneezy, and Michael A. Kuhn. 2012. "Experimental Methods: BetweenSubject and Within-Subject Design." Journal of Economic Behavior \& Organization 81(1):1-8.

Chassonnery-Zaïgouche, Cléo. 2020. "How Economists Entered the 'Numbers Game': Measuring Discrimination in the U.S. Courtrooms, 1971-1989." Journal of the History of Economic Thought 42(2):229-59.

Coate, Stephen, and Glenn C. Loury. 1993. "Will Affirmative-Action Policies Eliminate Negative Stereotypes?” The American Economic Review 83(5):1220-40.

Coffman, Katherine B., Christine L. Exley, and Muriel Niederle. 2020. Forthcoming. "The Role of Beliefs in Driving Gender Discrimination." Management Science.

Cornell, Bradford, and Ivo Welch. 1996. "Culture, Information, and Screening Discrimination." Journal of Political Economy 104(3):542-71.

Correll, Shelley J. 2017. "SWS 2016 Feminist Lecture: Reducing Gender Biases in Modern Workplaces: A Small Wins Approach to Organizational Change." Gender \& Society 31(6):72550 .

Correll, Shelley J., and Stephen Benard. 2006. "Biased Estimators? Comparing Status and Statistical Theories of Gender Discrimination.” Pp. 89-116 in Advances in Group Processes, Vol. 23, edited by S. R. Thye and E. J. Lawler. Bingley, UK: Emerald Group Publishing (https://doi.org/10.1016/S0882-6145(06)23004-2). 
Cowen, Tyler, and Alex Tabarrok. 2015. Modern Principles of Economics. New York: Worth Publishers.

Crandall, Christian S., and Amy Eshleman. 2003. "A Justification-Suppression Model of the Expression and Experience of Prejudice." Psychological Bulletin 129(3):414-46.

Dobbin, Frank. 1994a. "Cultural Models of Organization: The Social Construction of Rational Organizing Principles." Pp. 117-41 in The Sociology of Culture: Emerging Theoretical Perspectives, edited by D. Crane. Oxford, UK: Basil Blackwell.

Dobbin, Frank. 1994b. Forging Industrial Policy: The United States, Britain, and France in the Railway Age. Cambridge, UK: Cambridge University Press.

Dobbin, Frank. 2001. "Do the Social Sciences Shape Corporate Anti-Discrimination Practice: The United States and France." Comparative Labor Law \& Policy Journal 23(3):829-64.

Dobbin, Frank. 2009. Inventing Equal Opportunity. Princeton, NJ: Princeton University Press.

Dobbin, Frank, and Jiwook Jung. 2010. "The Misapplication of Mr. Michael Jensen: How Agency Theory Brought Down the Economy and Why It Might Again." Markets on Trial: The Economic Sociology of the U.S. Financial Crisis (Research in the Sociology of Organizations) 30B:29-64.

England, Paula. 1994. "Neoclassical Economists' Theories of Discrimination." Pp. 59-70 in Equal Employment Opportunity: Labor Market Discrimination and Public Policy. New York: Aldine de Gruyter.

England, Paula, and Peter Lewin. 1989. "Economic and Sociological Views of Discrimination in Labor Markets: Persistence or Demise?" Sociological Spectrum 9(3):239-257.

Ewens, Michael, Bryan Tomlin, and Liang Choon Wang. 2013. "Statistical Discrimination or Prejudice? A Large Sample Field Experiment." The Review of Economics and Statistics 96(1):119-34.

Felin, Teppo, and Nicolai J. Foss. 2009. "Performativity of Theory, Arbitrary Conventions, and Possible Worlds: A Reality Check.” Organization Science 20(3):676-78.

Fernandez, Roberto M., and Jason Greenberg. 2013. "Race, Network Hiring, and Statistical Discrimination." Pp. 81-102 in Networks, Work and Inequality, Vol. 24, Research in the Sociology of Work, edited by M. Steve. Bingley, UK: Emerald Group Publishing Limited.

Ferraro, Fabrizio, Jeffrey Pfeffer, and Robert I. Sutton. 2005. "Economics Language and Assumptions: How Theories Can Become Self-Fulfilling." Academy of Management Review 30(1):8-24.

Ferraro, Fabrizio, Jeffrey Pfeffer, and Robert I. Sutton. 2009. "How and Why Theories Matter: A Comment on Felin and Foss (2009)." Organization Science 20(3):669-675.

Fetterolf, Janell C., and Laurie A. Rudman. 2017. "Exposure to Sexual Economics Theory Promotes a Hostile View of Heterosexual Relationships." Psychology of Women Quarterly 41(1):77-88. 
Fligstein, Neil. 1993. The Transformation of Corporate Control. Cambridge, MA: Harvard University Press.

Fourcade, Marion. 2009. Economists and Societies: Discipline and Profession in the United States, Britain, and France, 1890s to 1990s. Princeton, NJ: Princeton University Press.

Fourcade, Marion. 2016. “Ordinalization: Lewis A. Coser Memorial Award for Theoretical Agenda Setting 2014.” Sociological Theory 34(3):175-95.

Fourcade, Marion, and Kieran Healy. 2013. "Classification Situations: Life-Chances in the Neoliberal Era.” Accounting, Organizations and Society 38(8):559-72.

Fourcade, Marion, and Kieran Healy. 2017. "Seeing Like a Market." Socio-Economic Review 15(1):9-29.

Fourcade, Marion, Etienne Ollion, and Yann Algan. 2015. "The Superiority of Economists." Journal of Economic Perspectives 29(1):89-114.

Frank, Björn, and Günther G. Schulze. 2000. "Does Economics Make Citizens Corrupt?” Journal of Economic Behavior \& Organization 43(1):101-13.

Frank, Robert H., Thomas Gilovich, and Dennis T. Regan. 1993. "Does Studying Economics Inhibit Cooperation?” The Journal of Economic Perspectives 7(2):159-71.

Gorman, Elizabeth H. 2005. "Gender Stereotypes, Same-Gender Preferences, and Organizational Variation in the Hiring of Women: Evidence from Law Firms." American Sociological Review 70(4):702-28.

Green, Tom L. 2012. "Introductory Economics Textbooks: What Do They Teach about Sustainability?” International Journal of Pluralism and Economics Education 3(2):189-223.

Greenwald, Anthony G., and Mahzarin R. Banaji. 1995. "Implicit Social Cognition: Attitudes, Self-Esteem, and Stereotypes.” Psychological Review 102(1):4-27.

Guillén, Mauro F. 1994. Models of Management: Work, Authority, and Organization in a Comparative Perspective. Chicago: University of Chicago Press.

Guryan, Jonathan, and Kerwin Kofi Charles. 2013. "Taste-Based or Statistical Discrimination: The Economics of Discrimination Returns to Its Roots.” The Economic Journal 123(572):F41732.

Harford, Tim. 2008. The Logic of Life: The Rational Economics of an Irrational World. New York: Random House.

Hindlian, Amanda, Sandra Lawson, Sonya Banerjee, Deborah Mirabal, Hui Shan, and Emma Campbell-Mohn. 2018. "Closing the Gender Gaps: Advancing Women in Corporate America." Goldman Sachs, Global Markets Institute, New York.

Hirschman, Daniel, and Elizabeth Popp Berman. 2014. "Do Economists Make Policies? On the Political Effects of Economics.” Socio-Economic Review 12(4):779-811.

Hirschman, Daniel, and Emily Adlin Bosk. 2020. "Standardizing Biases: Selection Devices and the Quantification of Race." Sociology of Race and Ethnicity 6(3):348-64. 
Hitlin, Steven, and Stephen Vaisey. 2013. "The New Sociology of Morality." Annual Review of Sociology 39(1):51-68.

Hollis, Martin. 1987. The Cunning of Reason. Cambridge, UK: Cambridge University Press.

Jung, Jiwook, and Frank Dobbin. 2016. "Agency Theory as Prophecy: How Boards, Analysts, and Fund Managers Perform Their Roles." Seattle University Law Review 39(2):291-320.

Jung, Jiwook, and Taekjin Shin. 2019. "Learning Not to Diversify: The Transformation of Graduate Business Education and the Decline of Diversifying Acquisitions." Administrative Science Quarterly 64(2):337-69.

Kalev, Alexandra, Frank Dobbin, and Erin Kelly. 2006. "Best Practices or Best Guesses? Assessing the Efficacy of Corporate Affirmative Action and Diversity Policies." American Sociological Review 71(4):589-617.

Kiviat, Barbara. 2019. "The Moral Limits of Predictive Practices: The Case of Credit-Based Insurance Scores.” American Sociological Review 84(6):1134-58.

Krippendorff, Klaus. 2004. Content Analysis: An Introduction to Its Methodology, 2nd ed. Thousand Oaks, CA: Sage.

Krueger, Alan. 2002. "Economic Scene; Sticks and Stones Can Break Bones, but the Wrong Name Can Make a Job Hard to Find." The New York Times, December 12, p. C2.

Kulas, John T., and Alicia A. Stachowski. 2009. "Middle Category Endorsement in OddNumbered Likert Response Scales: Associated Item Characteristics, Cognitive Demands, and Preferred Meanings." Journal of Research in Personality 43(3):489-93.

Kunda, Ziva, and Steven J. Spencer. 2003. "When Do Stereotypes Come to Mind and When Do They Color Judgment? A Goal-Based Theoretical Framework for Stereotype Activation and Application." Psychological Bulletin 129(4):522-44.

Leins, Casey. 2019. "More Data Needed to Determine Whether 'Ban the Box' Laws Work." Retrieved January 15, 2020 (https://www.usnews.com/news/best-states/articles/2019-09-10/banthe-box-laws-could-negatively-impact-minorities).

Li, Jun, Dennis Zhang, and Ruomeng Cui. 2017. "A Better Way to Fight Discrimination in the Sharing Economy." Harvard Business Review, February 27.

Light, Ryan, Vincent J. Roscigno, and Alexandra Kalev. 2011. "Racial Discrimination, Interpretation, and Legitimation at Work." The ANNALS of the American Academy of Political and Social Science 634(1):39-59.

Lundberg, Shelly J., and Richard Startz. 1983. "Private Discrimination and Social Intervention in Competitive Labor Markets." The American Economic Review 73(3):340-47.

Mackenzie, Donald. 2008. An Engine, Not a Camera: How Financial Models Shape Markets. Cambridge, MA: MIT Press.

Maitzen, Stephen. 1991. "The Ethics of Statistical Discrimination.” Social Theory and Practice 17(1):23-45. 
Marglin, Stephen A. 2008. The Dismal Science: How Thinking Like an Economist Undermines Community. Cambridge, MA: Harvard University Press.

Massey, Douglas, and Nancy A. Denton. 1993. American Apartheid: Segregation and the Making of the Underclass. Cambridge, MA: Harvard University Press.

McCall, Leslie, Derek Burk, Marie Laperrière, and Jennifer A. Richeson. 2017. "Exposure to Rising Inequality Shapes Americans' Opportunity Beliefs and Policy Support." Proceedings of the National Academy of Sciences 114(36):9593-98.

McCloskey, Donald N. 1984. "The Literary Character of Economics.” Daedalus 113(3):97-119.

McCloskey, Donald N. 1990. "Storytelling in Economics." Pp. 5-22 in Narrative in Culture, edited by C. Nash and M. Warner. London, UK: Routledge.

Merton, Robert K. 1948. “The Self-Fulfilling Prophecy.” The Antioch Review 8(2):193-210.

Meyer, John W., and Brian Rowan. 1977. "Institutionalized Organizations: Formal Structure as Myth and Ceremony." American Journal of Sociology 83(2):340-63.

Miller, Dale T. 1999. “The Norm of Self-Interest.” American Psychologist 54(12):1053-60.

Mirowski, Philip, and Edward Nik-Khah. 2007. "Markets Made Flesh: Performativity, and a Problem in Science Studies, Augmented with Consideration of the FCC Auctions." Pp. 190-224 in Do Economists Make Markets? On the Performativity of Economics, edited by D. MacKenzie, F. Muniesa, and L. Siu. Princeton, NJ: Princeton University Press.

Moss, Philip, and Chris Tilly. 2001. Stories Employers Tell: Race, Skill, and Hiring in America. New York: Russell Sage Foundation.

Mummolo, Jonathan, and Erik Peterson. 2019. "Demand Effects in Survey Experiments: An Empirical Assessment." American Political Science Review 113(2):517-29.

National Research Council. 2004. Measuring Racial Discrimination. Washington, DC: National Academies Press.

Newman, Leonard S., Mingxuan Tan, Tracy L. Caldwell, Kimberley J. Duff, and E. Samuel Winer. 2018. "Name Norms: A Guide to Casting Your Next Experiment." Personality and Social Psychology Bulletin 44(10):1435-48.

Norman, Peter. 2003. "Statistical Discrimination and Efficiency." The Review of Economic Studies 70(3):615-27.

Orne, Martin T. 1962. "On the Social Psychology of the Psychological Experiment: With Particular Reference to Demand Characteristics and Their Implications." American Psychologist 17(11):776-83.

Oyer, Paul. 2014. Everything I Ever Needed to Know about Economics I Learned from Online Dating. Boston, MA: Harvard Business Review Press.

Pager, Devah. 2016. "Are Firms That Discriminate More Likely to Go Out of Business?" Sociological Science 3:849-59. 
Pager, Devah, and Diana Karafin. 2009. "Bayesian Bigot? Statistical Discrimination, Stereotypes, and Employer Decision Making." The ANNALS of the American Academy of Political and Social Science 621(1):70-93.

Pager, Devah, and Lincoln Quillian. 2005. "Walking the Talk? What Employers Say versus What They Do." American Sociological Review 70(3):355-80.

Pager, Devah, and Hana Shepherd. 2008. "The Sociology of Discrimination: Racial Discrimination in Employment, Housing, Credit, and Consumer Markets." Annual Review of Sociology 34(1):181-209.

Palan, Stefan, and Christian Schitter. 2018. "Prolific.ac: A Subject Pool for Online Experiments." Journal of Behavioral and Experimental Finance 17:22-27.

Pedulla, David S. 2014. "The Positive Consequences of Negative Stereotypes: Race, Sexual Orientation, and the Job Application Process." Social Psychology Quarterly 77(1):75-94.

Pedulla, David S. 2020. Making the Cut: Hiring Decisions, Bias, and the Consequences of Nonstandard, Mismatched, and Precarious Employment. Princeton, NJ: Princeton University Press.

Peer, Eyal, Laura Brandimarte, Sonam Samat, and Alessandro Acquisti. 2017. "Beyond the Turk: Alternative Platforms for Crowdsourcing Behavioral Research." Journal of Experimental Social Psychology 70:153-63.

Petersen, Trond, and Ishak Saporta. 2004. "The Opportunity Structure for Discrimination." American Journal of Sociology 109(4):852-901.

Phelps, Edmund S. 1972. "The Statistical Theory of Racism and Sexism." The American Economic Review 62(4):659-61.

Quadlin, Natasha. 2018. “The Mark of a Woman's Record: Gender and Academic Performance in Hiring." American Sociological Review 83(2):331-60.

Quillian, Lincoln. 2006. "New Approaches to Understanding Racial Prejudice and Discrimination." Annual Review of Sociology 32(1):299-328.

Quillian, Lincoln, Devah Pager, Ole Hexel, and Arnfinn H. Midtbøen. 2017. "Meta-Analysis of Field Experiments Shows No Change in Racial Discrimination in Hiring over Time."

Proceedings of the National Academy of Sciences 114(41):10870-75.

Ray, Victor. 2019. “A Theory of Racialized Organizations.” American Sociological Review 84(1):26-53.

Reskin, Barbara. 2012. "The Race Discrimination System.” Annual Review of Sociology 38(1):17-35.

Ridgeway, Cecilia L. 1997. "Interaction and the Conservation of Gender Inequality: Considering Employment." American Sociological Review 62(2):218-35.

Ridgeway, Cecilia L. 2001. "Gender, Status, and Leadership." Journal of Social Issues 57(4):637-55. 
Ridgeway, Cecilia L. 2011. Framed by Gender: How Gender Inequality Persists in the Modern World. Oxford, UK: Oxford University Press.

Ridgeway, Cecilia L., and Shelley J. Correll. 2004. "Unpacking the Gender System: A Theoretical Perspective on Gender Beliefs and Social Relations." Gender \& Society 18(4):510 31.

Ridgeway, Cecilia L., and Lynn Smith-Lovin. 1999. "The Gender System and Interaction.” Annual Review of Sociology 25(1):191-216.

Rissing, Ben A., and Emilio J. Castilla. 2014. "House of Green Cards: Statistical or PreferenceBased Inequality in the Employment of Foreign Nationals." American Sociological Review 79(6):1226-55.

Rivera, Lauren A. 2016. Pedigree: How Elite Students Get Elite Jobs. Princeton, NJ: Princeton University Press.

Rivera, Lauren A. 2020. "Employer Decision Making." Annual Review of Sociology 46(1):21532.

Rivera, Lauren A., and András Tilcsik. 2016. "Class Advantage, Commitment Penalty: The Gendered Effect of Social Class Signals in an Elite Labor Market." American Sociological Review 81(6):1097-1131.

Rivera, Lauren A., and András Tilcsik. 2019. "Scaling Down Inequality: Rating Scales, Gender Bias, and the Architecture of Evaluation." American Sociological Review 84(2):248-74.

Roscigno, Vincent J. 2007. The Face of Discrimination: How Race and Gender Impact Work and Home Lives. Lanham, MD: Rowman \& Littlefield.

Ryan, Carey. 2003. "Stereotype Accuracy." European Review of Social Psychology, 13(1):75109.

Schudson, Michael. 1989. "How Culture Works: Perspectives from Media Studies on the Efficacy of Symbols.” Theory and Society 18(2):153-80.

Scott, W. Richard. 2013. Institutions and Organizations: Ideas, Interests, and Identities. Thousand Oaks CA: SAGE Publications.

Small, Mario L., and Devah Pager. 2020. "Sociological Perspectives on Racial Discrimination." Journal of Economic Perspectives 34(2):49-67.

Soffen, Kim. 2016. "The Big Question about Why Police Pull Over so Many Black Drivers." Washington Post, July 8.

Starr, Sonja B. 2014. "Evidence-Based Sentencing and the Scientific Rationalization of Discrimination." Stanford Law Review 66(4):803-72.

Stets, Jan E., and Michael J. Carter. 2012. "A Theory of the Self for the Sociology of Morality." American Sociological Review 77(1):120-40. 
Sztompka, Piotr. 1991. Society in Action: The Theory of Social Becoming. Chicago: University of Chicago Press.

The Economist. 2014. “(The Right Sort of) Help Wanted.” The Economist, June 11.

Turco, Catherine J. 2010. "Cultural Foundations of Tokenism: Evidence from the Leveraged Buyout Industry.” American Sociological Review 75(6):894-913.

Weber, Max. 1905. The Protestant Ethic and the Spirit of Capitalism. New York: Scribner's.

Zelizer, Viviana A. Rotman. 1979. Morals and Markets: The Development of Life Insurance in the United States. New York: Columbia University Press.

Zizzo, Daniel John. 2010. "Experimenter Demand Effects in Economic Experiments."

Experimental Economics 13(1):75-98.

Zuckerman, Ezra W. 2010. "What If We Had Been in Charge? The Sociologist as Builder of Rational Institutions." Pp. 359-78 in Markets on Trial: The Economic Sociology of the US Financial Crisis. Bingley, UK: Emerald Group Publishing. 
Table 1. Demographic Characteristics of Study Participants

\begin{tabular}{lcc} 
& $\begin{array}{c}\text { Parts 1 and } 2 \\
(n=2,249)\end{array}$ & $\begin{array}{c}\text { Part } 3^{\mathrm{a}} \\
(n=1,645)\end{array}$ \\
\hline Gender (percentage) & & \\
Female & 45.98 & 45.96 \\
Male & 52.96 & 53.01 \\
Other & 1.07 & 1.03 \\
Race/ethnicity (percentage) & & \\
American Indian/Alaska Native & .40 & .36 \\
Asian/Pacific Islander & 9.43 & 9.24 \\
Black/African American & 6.67 & 6.50 \\
Hispanic/Latino & 6.71 & 6.32 \\
White/Caucasian & 74.43 & 75.26 \\
Other & 2.36 & 2.31 \\
Age (mean and SD) & $38.20(10.87)$ & $38.27(10.87)$ \\
\hline Note: Follwing
\end{tabular}

Note: Following the preregistered plan, 2,500 participants were recruited for the study. Respondents who failed any of the comprehension check questions were dropped from the sample. The descriptive statistics displayed in this table refer to participants who were retained for the analysis.

${ }^{a}$ As noted earlier, Part 3 participants were a subset of respondents who had completed Parts 1 and 2 . For each variable listed in this table, I used a test of proportions (or, in the case of age, a $t$-test) to test for differences between participants who completed Parts 1 and 2 only and those who agreed to participate in Part 3 as well. I could not reject the null hypothesis of equal proportions (or, in the case of age, the null hypothesis of equal means) for any of these demographic characteristics. 
Table 2. Acceptance of Stereotyping, Perceived Accuracy of Stereotypes, and Number of Women Hired, by Experimental Condition

\begin{tabular}{|c|c|c|c|c|c|c|}
\hline & \multicolumn{2}{|c|}{ Acceptance of Stereotyping ${ }^{\mathrm{a}}$} & \multicolumn{2}{|c|}{ Perceived Accuracy of Stereotypes ${ }^{\mathrm{a}}$} & \multicolumn{2}{|c|}{ Number of Women Hired ${ }^{b}$} \\
\hline & $\begin{array}{l}\text { Mean } \\
(\mathrm{SD})\end{array}$ & $\begin{array}{l}\text { Mean difference } \\
\text { from condition } 1 \\
\quad(p \text {-value })^{c}\end{array}$ & $\begin{array}{l}\text { Mean } \\
(\mathrm{SD})\end{array}$ & $\begin{array}{l}\text { Mean difference } \\
\text { from condition } 1 \\
(p \text {-value })^{c}\end{array}$ & $\begin{array}{l}\text { Mean } \\
(\mathrm{SD})\end{array}$ & $\begin{array}{c}\text { Mean difference from } \\
\text { condition } 1 \\
(p \text {-value })^{\mathrm{c}}\end{array}$ \\
\hline 1. Statistical discrimination & $\begin{array}{l}3.67 \\
(.93)\end{array}$ & & $\begin{array}{l}3.61 \\
(1.05)\end{array}$ & & $\begin{array}{l}1.82 \\
(.68)\end{array}$ & \\
\hline 2. Nontreatment & $\begin{array}{l}3.36 \\
(.92)\end{array}$ & $\begin{array}{l}-.31 \\
(<.001)\end{array}$ & $\begin{array}{c}3.30 \\
(1.01)\end{array}$ & $\begin{array}{l}-.31 \\
(<.001)\end{array}$ & $\begin{array}{l}2.01 \\
(.75)\end{array}$ & $\begin{array}{c}.19 \\
(<.001)\end{array}$ \\
\hline 3. Taste-based discrimination & $\begin{array}{c}3.36 \\
(1.01)\end{array}$ & $\begin{array}{l}-.30 \\
(<.001)\end{array}$ & $\begin{array}{c}3.23 \\
(1.11)\end{array}$ & $\begin{array}{l}-.38 \\
(<.001)\end{array}$ & $\begin{array}{l}2.03 \\
(.66)\end{array}$ & $\begin{array}{l}.21 \\
(<.001)\end{array}$ \\
\hline $\begin{array}{l}\text { 4. Statistical discrimination with } \\
\text { critical commentary }\end{array}$ & $\begin{array}{l}3.46 \\
(.97)\end{array}$ & $\begin{array}{l}-.21 \\
(.001)\end{array}$ & $\begin{array}{l}3.43 \\
(1.08)\end{array}$ & $\begin{array}{l}-.18 \\
(.034)\end{array}$ & $\begin{array}{l}1.99 \\
(.67)\end{array}$ & $\begin{array}{l}.16 \\
(.004)\end{array}$ \\
\hline
\end{tabular}

$N=2,249$. The number of participants varied slightly across the four conditions ( $n=577, n=586, n=540, n=546$, respectively) because of simple random assignment into conditions as well as some differences in the rate of passing comprehension checks across the conditions.

${ }^{\mathrm{b}} N=1,645$. The number of participants varied slightly across the four conditions ( $n=428, n=419, n=404, n=394$, respectively) because of simple random assignment into conditions as well as some differences in the rate of passing comprehension checks and the rate of participating in the hiring simulation across the conditions.

${ }^{c}$ The $p$-values for differences in means were calculated using one-way analysis of variance (ANOVA) with Bonferroni multiple comparison tests, which apply corrections to account for the fact that multiple comparisons are being made. Using Scheffe or Sidak multiple comparison tests led to only minor differences in $p$-values and did not substantively affect the conclusions. ANOVA results indicated that the means were not all equal, implying that the effect of at least one condition differed from zero for acceptance of stereotyping $(\mathrm{F}(3,2245)=12.95, p<.001)$, perceived accuracy of stereotypes $(\mathrm{F}(3,2245)=13.92, p<.001)$, and the number of women selected in the hiring simulation $(\mathrm{F}(3,1476)=15.28, p<.001)$. 
Table 3. Regression Models Predicting Acceptance of Stereotyping, Perceived Accuracy of Stereotypes, and Number of Women Hired

Perceived

Acceptance of Accuracy of Number of Women Stereotyping (OLS) Stereotypes (OLS) $\quad$ Hired (Poisson)

\begin{tabular}{|c|c|c|c|}
\hline \multicolumn{4}{|l|}{ Experimental Conditions } \\
\hline \multirow[t]{2}{*}{ Nontreatment } & $-.293 * * *$ & $-.295 * * *$ & $.094 * * *$ \\
\hline & $(.053)$ & $(.060)$ & $(.025)$ \\
\hline \multirow{2}{*}{ Taste-based discrimination } & $-.308 * * *$ & $-.377 * * *$ & $.104 * * *$ \\
\hline & $(.057)$ & $(.064)$ & $(.024)$ \\
\hline \multirow{2}{*}{ Statistical discrimination with critical commentary } & $-.206 * * *$ & $-.169 * *$ & $.080^{* * *}$ \\
\hline & $(.056)$ & $(.063)$ & $(.024)$ \\
\hline \multicolumn{4}{|l|}{ Participant Characteristics } \\
\hline \multirow[t]{2}{*}{ Female } & $-.328 * * *$ & $-.340 * * *$ & $.092 * * *$ \\
\hline & $(.040)$ & $(.045)$ & $(.017)$ \\
\hline \multirow[t]{2}{*}{ Other gender } & $-.961 * * *$ & $-1.121 * * *$ & $.338 * * *$ \\
\hline & $(.190)$ & $(.166)$ & $(.072)$ \\
\hline \multirow{2}{*}{ American Indian/Alaska Native } & .124 & .031 & .147 \\
\hline & $(.326)$ & $(.442)$ & $(.181)$ \\
\hline \multirow[t]{2}{*}{ Asian/Pacific Islander } & .105 & .095 & -.019 \\
\hline & $(.055)$ & $(.068)$ & $(.029)$ \\
\hline \multirow[t]{2}{*}{ Black/African American } & $-.249 * *$ & $-.263 * *$ & -.007 \\
\hline & $(.081)$ & $(.087)$ & $(.034)$ \\
\hline \multirow[t]{2}{*}{ Hispanic/Latino } & -.019 & -.000 & -.030 \\
\hline & $(.076)$ & $(.081)$ & $(.034)$ \\
\hline \multirow[t]{2}{*}{ Other race } & .093 & -.148 & .026 \\
\hline & $(.158)$ & $(.166)$ & $(.059)$ \\
\hline \multirow[t]{2}{*}{ Age } & .006 & .002 & .001 \\
\hline & $(.012)$ & $(.014)$ & $(.005)$ \\
\hline \multirow[t]{2}{*}{$\mathrm{Age}^{2}$} & -.000 & .000 & -.000 \\
\hline & $(.000)$ & $(.000)$ & $(.000)$ \\
\hline \multirow[t]{2}{*}{ Constant } & $3.728 * * *$ & $3.713 * * *$ & $.541 * * *$ \\
\hline & $(.252)$ & $(.287)$ & $(.111)$ \\
\hline Observations & 2,249 & 2,249 & 1,645 \\
\hline
\end{tabular}

Note: Unstandardized coefficients are displayed. The omitted reference categories are statistical discrimination (for the experimental conditions), male (for participant gender), and White/Caucasian (for participant race). Robust standard errors are in parentheses. ${ }^{*} p<.05 ; * *<.01 ; * * *<.001$ (two-tailed).

Table 4. Decomposition of the Effect of Statistical Discrimination Theory on the Number of Women Hired

\begin{tabular}{lcccc}
\hline & Direct Effect & Indirect Effect & Total Effect & Percent Mediated \\
\hline Exposure to statistical & $-.078^{*}$ & $-.104 * * *$ & $-.182 * * *$ & $-.104 /-.182=$ \\
discrimination theory & $(.035)$ & $(.013)$ & $(.037)$ & $57.1 \%$ \\
\hline
\end{tabular}

Note: Coefficient estimates are from the structural equation model summarized in Figure 2. Observed information matrix (OIM) standard errors are in parentheses. The indirect effect captures the paths that led from the treatment (i.e., exposure to statistical discrimination theory) to the number of women hired through the attitudinal variables (i.e., acceptance of stereotyping and perceived accuracy of stereotypes). The path that ran through the acceptance of stereotyping and the path that ran through the perceived accuracy of stereotypes were responsible for a roughly similar proportion of the indirect effect (44 versus 56 percent of the indirect effect, respectively). $* p<.05 ; * * p<.01 ; * * * p<.001$ (two-tailed). 
Table 5. Average Number of Responses in Each Response Category for the Acceptance of Stereotyping Scale and the Perceived Accuracy of Stereotypes Scale

\begin{tabular}{|c|c|c|c|}
\hline & $\begin{array}{c}\text { Control } \\
\text { Conditions }\end{array}$ & $\begin{array}{c}\text { Statistical } \\
\text { Discrimination } \\
\text { Condition }\end{array}$ & Difference \\
\hline \multicolumn{4}{|l|}{ Acceptance of Stereotyping Scale } \\
\hline Strongly disagree & $\begin{array}{c}1.54 \\
(2.49)\end{array}$ & $\begin{array}{c}1.11 \\
(2.05)\end{array}$ & $\begin{array}{c}-.43 * * * \\
(.12)\end{array}$ \\
\hline Disagree & $\begin{array}{c}2.78 \\
(2.53)\end{array}$ & $\begin{array}{c}2.24 \\
(2.24)\end{array}$ & $\begin{array}{c}-.54 * * * \\
(.12)\end{array}$ \\
\hline Somewhat disagree & $\begin{array}{c}2.37 \\
(2.03)\end{array}$ & $\begin{array}{c}2.34 \\
(1.78)\end{array}$ & $\begin{array}{c}-.02 \\
(.09)\end{array}$ \\
\hline Neither agree nor disagree & $\begin{array}{c}1.71 \\
(1.98)\end{array}$ & $\begin{array}{c}2.03 \\
(2.13)\end{array}$ & $\begin{array}{l}.32 * * \\
(.10)\end{array}$ \\
\hline Somewhat agree & $\begin{array}{c}2.27 \\
(2.09)\end{array}$ & $\begin{array}{c}2.73 \\
(2.05)\end{array}$ & $\begin{array}{l}.46^{* * *} \\
(.10)\end{array}$ \\
\hline Agree & $\begin{array}{l}1.03 \\
(1.47)\end{array}$ & $\begin{array}{c}1.22 \\
(1.62)\end{array}$ & $\begin{array}{l}.19 * * \\
(.07)\end{array}$ \\
\hline Strongly agree & $\begin{array}{l}.31 \\
(.94)\end{array}$ & $\begin{array}{l}.33 \\
(.87)\end{array}$ & $\begin{array}{l}.02 \\
(.04)\end{array}$ \\
\hline \multicolumn{4}{|l|}{ Perceived Accuracy of Stereotypes Scale } \\
\hline Strongly disagree & $\begin{array}{c}1.33 \\
(2.57)\end{array}$ & $\begin{array}{c}.99 \\
(2.25)\end{array}$ & $\begin{array}{l}-.34 * * \\
(.12)\end{array}$ \\
\hline Disagree & $\begin{array}{c}2.96 \\
(3.05)\end{array}$ & $\begin{array}{c}2.32 \\
(2.76)\end{array}$ & $\begin{array}{c}-.65^{* * * *} \\
(.14)\end{array}$ \\
\hline Somewhat disagree & $\begin{array}{c}2.54 \\
(2.34)\end{array}$ & $\begin{array}{c}2.37 \\
(2.25)\end{array}$ & $\begin{array}{c}-.18 \\
(.11)\end{array}$ \\
\hline Neither agree nor disagree & $\begin{array}{c}1.95 \\
(2.22)\end{array}$ & $\begin{array}{c}2.32 \\
(2.50)\end{array}$ & $\begin{array}{l}.37 * * * \\
(.11)\end{array}$ \\
\hline Somewhat agree & $\begin{array}{c}2.33 \\
(2.59)\end{array}$ & $\begin{array}{c}2.92 \\
(2.81)\end{array}$ & $\begin{array}{l}.59 * * * \\
(.13)\end{array}$ \\
\hline Agree & $\begin{array}{c}.71 \\
(1.48)\end{array}$ & $\begin{array}{c}.91 \\
(1.73)\end{array}$ & $\begin{array}{l}.20 * * \\
(.07)\end{array}$ \\
\hline Strongly agree & $\begin{array}{l}.17 \\
(.81) \\
\end{array}$ & $\begin{array}{l}.17 \\
(.56) \\
\end{array}$ & $\begin{array}{l}.00 \\
(.04)\end{array}$ \\
\hline $\begin{array}{l}\text { Note: This table shows the mean numb } \\
\text { attitudinal dependent variables and dif } \\
\text { deviations (for the means) and standar } \\
\text { nontreatment, taste-based discriminati } \\
\text { discrimination condition, } n=577 \text {. } \\
{ }^{*} p<.05 ; * * p<.01 ; * * * p<.001 \text { (two }\end{array}$ & $\begin{array}{l}\text { response cate } \\
\text { between the } \\
\text { ifferences) ar } \\
\text { mination with }\end{array}$ & $\begin{array}{l}\text { reverse coding } \\
\text { condition and the } \\
\text { theses. In the con } \\
\text { ommentary condi }\end{array}$ & $\begin{array}{l}\text { opriate) fo } \\
\text { nditions. S } \\
\text { ons (which } \\
1,672 \text {. In t }\end{array}$ \\
\hline
\end{tabular}


Figure 1. Structure of the Experiment

\begin{tabular}{|c|c|c|c|}
\hline & PART 1 & PART 2 & PART 3 \\
\hline Purpose & Experimental manipulation & $\begin{array}{c}\text { Measurement of attitudes about } \\
\text { stereotypes }\end{array}$ & $\begin{array}{c}\text { Measurement of discriminatory } \\
\text { decisions }\end{array}$ \\
\hline Main content & $\begin{array}{c}\text { Exposure to statistical } \\
\text { discrimination theory or a control } \\
\text { condition }\end{array}$ & $\begin{array}{l}\text { Questionnaires about the } \\
\text { acceptance of stereotyping and } \\
\text { perceived accuracy of } \\
\text { stereotypes }\end{array}$ & $\begin{array}{l}\text { Hiring simulation with an } \\
\text { incentive to hire the most } \\
\text { productive workers }\end{array}$ \\
\hline Timing & $\begin{array}{c}\text { Launched with Part } 2 \text { as a bundle } \\
\text { of two (ostensibly) distinct } \\
\text { studies }\end{array}$ & $\begin{array}{c}\text { Launched with Part } 1 \text { as a bundle } \\
\text { of two (ostensibly) distinct } \\
\text { studies }\end{array}$ & $\begin{array}{l}\text { Launched one hour after Parts } 1 \\
\text { and } 2 \text { had been completed }\end{array}$ \\
\hline Cover story & $\begin{array}{l}\text { "A study of how people make } \\
\text { sense of ideas developed in the } \\
\text { natural and social sciences." }\end{array}$ & $\begin{array}{l}\text { "A study of how people make } \\
\text { decisions under uncertainty." }\end{array}$ & $\begin{array}{l}\text { "A hiring simulation with an } \\
\text { opportunity to earn a bonus." }\end{array}$ \\
\hline $\begin{array}{l}\text { New consent form at the } \\
\text { beginning }\end{array}$ & Yes & Yes & Yes \\
\hline $\begin{array}{l}\text { Unique font, color, and } \\
\text { design scheme }\end{array}$ & Yes & Yes & Yes \\
\hline
\end{tabular}

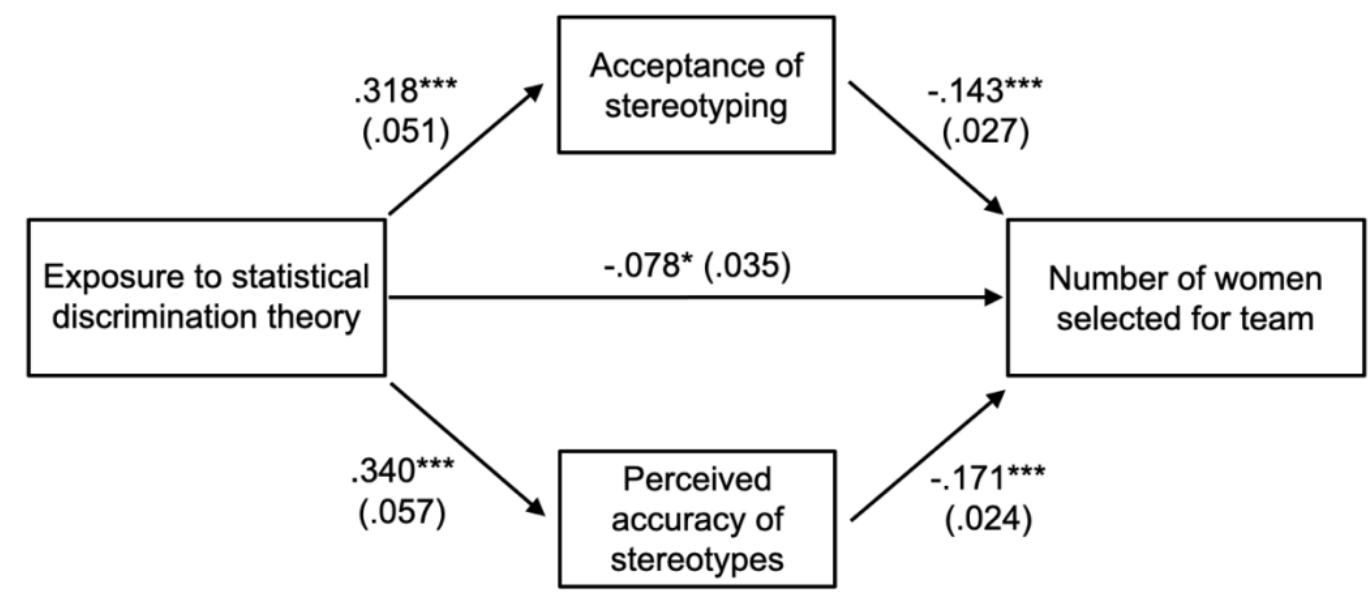

Figure 2. Path Analysis of the Effect of Exposure to Statistical Discrimination Theory on the Number of Women Hired Note: $N=1,645$. Results of a structural equation model, estimated with maximum likelihood, are displayed. Covariatesparticipant gender, race, age, and age squared-were included in the analysis but are omitted from this figure. Path coefficients are unstandardized. Observed information matrix (OIM) standard errors are in parentheses. The substantive conclusions were robust to use of bootstrapped standard errors and use of a Generalized Structural Equation Model (GSEM) with a Poisson regression.

$* p<.05 ; * *<.01 ; * * * p<.001$ (two-tailed). 